\title{
Pro-Oxidant Natural Products as Anticancer Agents
}

\author{
Carmen Martín-Cordero, Antonio José León-González, José Manuel Calderón-Montaño, \\ Estefania Burgos-Morón and Miguel López-Lázaro*
}

Department of Pharmacology, Faculty of Pharmacy, University of Seville, Seville, Spain

\begin{abstract}
Cancer cells produce high levels of reactive oxygen species (ROS) that lead to a state of increased basal oxidative stress. Since this state of oxidative stress makes cancer cells vulnerable to agents that further augment ROS levels, the use of pro-oxidant agents is emerging as an exciting strategy to selectively target tumor cells. Natural products have provided a significant contribution to the development of several drugs currently used in cancer chemotherapy. Although many natural products are known to affect the redox state of the cell, most studies on these compounds have focused on their antioxidant activity instead of on their pro-oxidant properties. This article provides an overview of natural products with pro-oxidant and anticancer activities, with special focus on plant secondary metabolites, and discusses their possible use as cancer chemotherapeutic agents.
\end{abstract}

Keywords: Alkaloids, cancer, hydrogen peroxide, phenolic compounds, plant secondary metabolites, prooxidant, reactive oxygen species, terpenoids.

\section{INTRODUCTION}

Cancer kills over seven million people worldwide every year [1]. The mortality rate of this disease has not changed much in the past few decades even in developed countries as the United States [2]. Although cancer therapy in the form of surgery or radiotherapy is effective when the disease is early detected, many cancers are still diagnosed when cells from a primary tumor have already metastasized to other parts of the body. The main form of treatment at this point is chemotherapy, which consists of delivering drugs systemically so that they can reach and kill the tumor cells. But most of these drugs cause severe side effects in patients and, therefore, need to be used at suboptimal levels. The low efficacy of chemotherapy in patients with advanced cancers is reflected in the low 5-year survival rates observed in these patients [2]. For example, cancer statistics show that the most commonly diagnosed cancer in the world is lung cancer [1], that approximately $50 \%$ of patients diagnosed with this type of cancer have distant metastasis [2] and that only 3\% of these patients manage to survive more than 5 years [2]. The low efficacy of cancer therapy for the treatment of patients with metastasis makes the development of novel chemotherapeutic agents necessary.

Despite the recent interest by pharmaceutical companies in molecular modeling, combinatorial chemistry and other synthetic chemistry techniques, natural products and medicinal plants continue to be an important source of new drugs. Natural products are not only used as therapeutic agents, but are also a source of lead compounds that have provided the basis for the semisynthesis or total synthesis of new drugs. An analysis of the sources of drugs approved from January

\footnotetext{
*Address correspondence to this author at the Department of Pharmacology, Faculty of Pharmacy, Profesor Garcia Gonzalez 2, 41012 Sevilla, Spain; Tel: + 349545563 48; Fax: + 34954556074 ;

E-mail: mlopezlazaro@us.es
}

1981 to the middle of October 2008 revealed that $6 \%$ of the 1024 new chemical entities were unmodified natural products and that only $37 \%$ were drugs not related to natural products $[3,4]$. The role these latter in drug discovery is particularly relevant in oncology. It is estimated that over the time frame from around the 1940s to 2006, of the 155 small molecules approved for cancer therapy, only $27 \%$ were not related to natural products [3]. The first plant-derived anticancer agents to advance into clinical use were the Vinca alkaloids vinblastine and vincristine. Other important plantderived anticancer compounds include paclitaxel (taxol), the epipodophyllotoxin derivative etoposide, and the camptothecin derivatives topotecan and irinotecan [5]. The mechanism of action of these drugs is considered to consist in the inhibition of microtubule assembly (Vinca alkaloids and paclitaxel), inhibition of DNA topoisomerase II (etoposide) and inhibition of DNA topoisomerase I (campothecin derivatives). Recent evidence suggests that the formation of reactive oxygen species (ROS) may also contribute to the anticancer effects of these drugs [6-8]. The induction of oxidative stress by pro-oxidant agents is indeed emerging as an attractive anticancer strategy that may be used to target cancer cells selectively [9-13]. After discussing the role of oxidative stress in cancer and the possible use of pro-oxidant agents in cancer therapy, this article provides an overview of pro-oxidant natural products with anticancer activity and examines their potential as cancer chemotherapeutic agents.

\section{OXIDATIVE STRESS IN CANCER CELLS}

Oxidative stress is an imbalance between the generation and elimination of reactive oxygen species in favor of the former, causing excessive oxidative damage to macromolecules, cells and tissues. Reactive oxygen species (ROS) is the collective term used to name oxygen radicals (including hydroxyl radical and superoxide radical) and some other nonradical derivatives of oxygen, such as hydrogen peroxide 
$\left(\mathrm{H}_{2} \mathrm{O}_{2}\right)$. ROS can easily generate free radicals (any species containing one or more unpaired electrons) and/or cause oxidative damage [14]. ROS are generated by all aerobic organisms and their production seems to be needed for signaltransduction pathways that regulate several different physiological processes. Excessive amounts of ROS, however, can start toxic and lethal chain reactions, which oxidize and disable structures that are required for cellular integrity and survival. ROS are generated in multiple compartments and by multiple enzymes within the cell. Important contributions include proteins within the plasma membrane, such as the growing family of NADPH oxidases; lipid metabolism within the peroxisomes; as well as the activity of various cytosolic enzymes such as cyclooxygenases. Although all these sources contribute to the overall ROS production, the vast majority of cellular ROS can be traced back to the mitochondria $[15,16]$.

Accumulating evidence indicates that cancer cells generate excessive levels of ROS and have a state of oxidative stress. Many malignant cells produce high levels of ROS in culture. For instance, Szatrowski and Nathan reported that several tumor cell lines, representing a variety of tissue types, constitutively produced large amounts of $\mathrm{H}_{2} \mathrm{O}_{2}$. They observed that the cumulative amount of $\mathrm{H}_{2} \mathrm{O}_{2}$ produced after $4 \mathrm{~h}$ by these tumor cells was comparable to the amount of $\mathrm{H}_{2} \mathrm{O}_{2}$ produced by similar numbers of phorbol ester-triggered neutrophils [17]. The increased production of ROS by cancer cells observed in vitro has also been found in vivo. For example, chronic lymphocytic leukemia cells freshly taken from patients showed increased ROS production compared with normal lymphocytes. This was also observed with Bcell lines from patients with Burkitt's lymphoma associated with Epstein-Barr virus infection and malignant B-cells from patients with hairy cell leukemia (see [18] and references therein). For solid tumors, however, demonstrating increased ROS production in vivo is difficult to achieve owing to methodological inadequacies, so most researchers have studied oxidative damage levels rather than ROS production. Such studies have shown increased levels of oxidative damage (e.g. 8OHdG) in human cancers and in animal cancers induced by a wide range of carcinogens (reviewed in [18]). Interestingly, the most important carcinogenic agents and behaviors induce oxidative stress, including most chemical carcinogens (e.g. $N$-nitrosamines, asbestos, arsenic), ultraviolet radiation, cancer-associated viruses or bacteria, inflammation, alcohol, tobacco smoke and obesity. It is also recognized that age is the principal risk factor for most cancers and that oxidative stress may be the most important causal factor in aging (see $[19,20]$ and references therein).

The increased levels of ROS of cancer cells seem to play a key role in cancer development $[12,18,21]$. ROS such as $\mathrm{H}_{2} \mathrm{O}_{2}$ can induce cell malignant transformation, and the malignant phenotype of tumor cells can be reversed by decreasing the levels of $\operatorname{ROS}[12,22-24]$. For instance, expression of the ROS generation system Nox1 in normal NIH3T3 fibroblasts resulted in cells with malignant characteristics that produced tumors in athymic mice. These transformed cells showed a 10-fold increase in $\mathrm{H}_{2} \mathrm{O}_{2}$ levels. When human catalase was expressed in these transformed cells, $\mathrm{H}_{2} \mathrm{O}_{2}$ concentration decreased, and the cells reverted to a normal appearance, the growth rate normalized, and cells no longer pro- duced tumors in athymic mice [24]. In addition, ROS have been shown to participate in the most relevant aspects of carcinogenesis. Most researchers consider that cancer is a genetic disease caused by the acquisition of multiple mutations in genes that control cell proliferation, cell death and genomic instability [25]. It is also accepted that cells must develop several acquired capabilities in order to become a malignant cancer: increased cell proliferation (caused, in part, by resistance to growth inhibition and independence from mitogenic stimulation), apoptosis resistance, cellular immortalization, increased angiogenesis, invasion and metastasis. In addition, genetic instability is considered to be a key event that enables the acquisition of these capabilities [26, 27]. Accumulating experimental data indicate that an increase in the cellular concentrations of ROS such as $\mathrm{H}_{2} \mathrm{O}_{2}$ can explain all these hallmarks of cancer. It is known that an increase in the levels of $\mathrm{H}_{2} \mathrm{O}_{2}$ can lead to DNA damage, mutations, and genetic instability [26-31]; $\mathrm{H}_{2} \mathrm{O}_{2}$-induced DNA damage seems to be mediated by hydroxyl radical generated from $\mathrm{H}_{2} \mathrm{O}_{2}$ by the Fenton reaction [28-30]. Several studies have also demonstrated that ROS can induce cell proliferation [31], apoptosis resistance [32, 33], increased angiogenesis [34, 35], and invasion and metastasis [36-38]. Indeed, these studies showed that an increase in the levels of $\mathrm{H}_{2} \mathrm{O}_{2^{-}}$ detoxifying enzymes could reduce cell proliferation, promote apoptosis, and inhibit invasion, metastasis and angiogenesis. In short, cancer cells produce high levels of ROS that lead to a state of increased basal oxidative stress. Such state of oxidative stress is induced by the most important human carcinogens and plays an important role in cancer development.

\section{SELECTIVE ANTICANCER ACTIVITY OF PRO- OXIDANT AGENTS}

Since cancer cells have increased levels of ROS that play an important role in carcinogenesis, agents with antioxidant activity may induce cancer preventive effects by reducing and/or preventing such increase in the cellular levels of ROS. Because pro-oxidant agents increase the cellular levels of ROS, it is recognized that these agents can induce carcinogenic effects. But when pro-oxidant agents increase the cellular levels of ROS to cytotoxic levels, these agents may induce selective killing of cancer cells and be therapeutically useful. It is important to mention that all these effects can be achieved by agents with both antioxidant and pro-oxidant properties (e.g. curcumin), which can act as cancer chemopreventive, carcinogenic, and chemotherapeutic agents mainly depending on the concentration by which they are used [12, 39].

The role of ROS in cancer therapy is increasingly being acknowledged and the induction of oxidative stress by prooxidant agents is emerging as an attractive anticancer strategy [9-12, 40-43]. Recent data suggests that ROS participate in the anticancer activity of many chemotherapeutic agents commonly used in the clinic, including paclitaxel, docetaxel, cisplatin, doxorubicin, arsenic trioxide, bortezomib, procarbazine and etoposide [6-8, 10, 40, 44-54]. For instance, although it has been known for many years that the microtubule protein tubulin is the therapeutic target for paclitaxel (taxol), recent experiments have shown that the accumulation of $\mathrm{H}_{2} \mathrm{O}_{2}$ is a crucial step for paclitaxel-induced cancer cell death both in vitro and in vivo $[6,8] . \mathrm{H}_{2} \mathrm{O}_{2}$ seems to be a 
key player in oxidative stress-induced cancer cell death. Many anticancer agents increase the levels of $\mathrm{H}_{2} \mathrm{O}_{2}[6,45$, 47], and $\mathrm{H}_{2} \mathrm{O}_{2}$ is known to be an efficient inducer of cell death in cancer cells $[12,48,55]$. Interestingly, cancer cells are more susceptible to $\mathrm{H}_{2} \mathrm{O}_{2}$-induced cell death than nonmalignant cells [56-58]. Using several cancer and normal cell lines, Chen et al. [56] observed that high concentrations of ascorbic acid selectively killed a variety of cancer cells and that this effect was mediated by $\mathrm{H}_{2} \mathrm{O}_{2}$. They showed, for instance, that a concentration of $50 \mu \mathrm{M} \mathrm{H}_{2} \mathrm{O}_{2}$ induced more percentage of cell death in Burkitt's lymphoma cells than $250 \mu \mathrm{M}$ in normal lymphocytes and normal monocytes [56]. This selective effect of $\mathrm{H}_{2} \mathrm{O}_{2}$ has also been observed in cells derived from solid tumors. Using lung cancer cells and nonmalignant lung fibroblasts under the same experimental conditions, we recently found that specific concentrations of $\mathrm{H}_{2} \mathrm{O}_{2}$ and of the $\mathrm{H}_{2} \mathrm{O}_{2}$-generating agent pyrogallol induced selective killing of the cancer cells [59].

It is not clear why specific concentrations of $\mathrm{H}_{2} \mathrm{O}_{2}$ (and of pro-oxidant agents) can kill cancer cells selectively. In vitro and in vivo data indicate that tumor cells produce higher concentrations of $\mathrm{H}_{2} \mathrm{O}_{2}$ than their normal counterparts $[17,18,31,60-62]$. This, and the fact that there is a threshold of $\mathrm{H}_{2} \mathrm{O}_{2}$ above which cells cannot survive, may explain why specific concentrations of $\mathrm{H}_{2} \mathrm{O}_{2}$ induce selective killing of cancer cells [12]. Excessive cellular accumulation of $\mathrm{H}_{2} \mathrm{O}_{2}$ may cause cell death through the induction of DNA damage, which seems to be mediated by hydroxyl radical generated from $\mathrm{H}_{2} \mathrm{O}_{2}$ in the presence of iron or copper (Fenton reaction) [28-30]. Unlike non-malignant cells, cancer cells have mutations in DNA repair genes and cannot properly repair specific types of DNA damage [25, 63]. It is possible that some cancers may have a reduced capacity to repair ROSinduced DNA damage and be more vulnerable than normal cells to the cytotoxic activity of ROS. It has also been proposed that the increased levels of copper found in various malignancies may explain why some pro-oxidant agents (e.g. plant polyphenols) can induce selective killing of cancer cells [64]. The increased levels of copper of cancer cells would favor the formation of higher levels of hydroxyl radical through the Fenton reaction.

\section{PRO-OXIDANT NATURAL PRODUCTS WITH ANTICANCER ACTIVITY}

An overview of natural products with both pro-oxidant and anticancer activities is presented in Table $\mathbf{1}$. The name of the natural product, the type of compound, the natural source (representative species) and the references are provided. The first part of the table comprises plant compounds of primary metabolism and their derivatives. Then, plant secondary metabolites, including phenolic compounds, terpenoids and alkaloids, are compiled. The last section includes other natural products from different natural sources (compounds of animal, microorganism, or marine origin, vitamins, etc). The mechanism involved in the generation of ROS is not available for most compounds and is not included. The general mechanisms involved in ROS generation by a variety of prooxidant agents (from natural and synthetic origin) have been discussed extensively elsewhere [42].
Some natural products reported in Table $\mathbf{1}$ are drugs currently used in cancer chemotherapy (e.g. paclitaxel, vincristine, vinblastine, bleomycin, mitomycin, doxorubicin, idarubicin, aclarubicin and actinomycin D). Others have entered clinical trials for the treatment of specific types of cancer (e.g. curcumin, epigallocatechin-3-gallate, genistein, resveratrol, camptothecin, perillil alcohol, licopene, phenylethyl isothiocyanate, sulforaphane, aplidin, eicosapentaenoic acid, linoleic acid, ursodeoxycholic acid, vitamin $\mathrm{C}$, vitamin $\mathrm{D}_{2}$ and vitamin $\mathrm{D}_{3}$; see http://clinicaltrials.gov/). The chemical structures of these compounds are represented in Fig. (1) and Fig. (2). The anticancer activity of most compounds compiled in Table $\mathbf{1}$ has only been evaluated in pre-clinical models.

It is important to mention that, although the pro-oxidant effect of a specific natural product may not be the most important cytotoxic mechanism of action, this pro-oxidant effect may be responsible for the selective anticancer activity of the compound. For instance, it is known that the main mechanism of action of paclitaxel consists in the inhibition of microtubule assembly. A drug that only inhibits microtubule assembly would be equally cytotoxic in cells with the same proliferating rate, as microtubules are necessary for cell proliferation. Because it is known that cancer cells are more vulnerable to paclitaxel than highly proliferating nonmalignant cells, it has been enigmatic for many years why this drug has certain selectivity for cancer cells [25]. Recently, it was observed that the accumulation of $\mathrm{H}_{2} \mathrm{O}_{2}$ is crucial for paclitaxel-induced cancer cell death both in vitro and in vivo $[6,8]$. Being well known that $\mathrm{H}_{2} \mathrm{O}_{2}$ can induce selective killing of cancer cells, it seems possible that paclitaxelinduced $\mathrm{H}_{2} \mathrm{O}_{2}$ production plays a role in the selective anticancer effects of this natural product.

Since the redox state of the cell is important for many cellular processes, it has been discussed that pro-oxidant agents may act as "dirty" drugs (agents that modulate multiple molecular targets through pleiotropic interactions). However, recent research suggests that this pleiotropic mode of action may be an advantage to overcome cancer cell drug resistance typical of drugs acting on just one target [42]. Although pro-oxidant agents could be used as stand-alone drugs, evidence suggests that they could also be used in combination [42]. Indeed, although ROS induce cancer cell death, tumor cells are known to develop mechanisms that prevent ROS from reaching cytotoxic levels. The glutathione and thioredoxin antioxidant systems are crucial for detoxifying ROS. These antioxidant systems are activated in cancer cells and play an important role in the development of resistance to many anticancer agents [65-71]. The possible drug resistance induced by pro-oxidant agents could be reduced with glycolysis inhibitors [13]. Evidence indicates that prooxidant agents can increase the cellular levels of $\mathrm{H}_{2} \mathrm{O}_{2}$ and that glycolysis inhibitors can reduce the capacity of cells to detoxify $\mathrm{H}_{2} \mathrm{O}_{2}$. Experimental data have shown that malignant cells are more susceptible to glucose deprivation than nontransformed cells, and that an increase in the levels of $\mathrm{H}_{2} \mathrm{O}_{2}$ may mediate the cytotoxic effect induced by glucose deprivation [62, 72-74]. Two possible mechanisms may explain why the activation of glycolysis plays an important function in protecting tumor cells from $\mathrm{H}_{2} \mathrm{O}_{2}$-induced cell death. First, the activation of glycolysis increases the formation of pyru- 
Table 1. Natural Products with Pro-Oxidant and Anticancer Activities

\begin{tabular}{|c|c|c|c|}
\hline Compound & Type of Compound & Natural Source & References \\
\hline \multicolumn{4}{|c|}{ Compounds of Primary Metabolism and derivatives } \\
\hline Ajoene & Organosulfur & Allium sativum (Alliaceae) & {$[83,84]$} \\
\hline Allicin & Organosulfur & Allium sativum (Alliaceae) & [85-87] \\
\hline Diallyl disulfide & Organosulfur & Allium spp. (Alliaceae) & {$[90,91]$} \\
\hline Dimethyl disulfide & Organosulfur & Allium spp. (Alliaceae) & [92] \\
\hline Jasmonic acid & Fatty acid & Jasminum spp. (Oleaceae), widespread & [93] \\
\hline Melatonin & Aminoacid & Prunus cerasus (Rosaceae) & {$[100,101]$} \\
\hline Methyl jasmonate & Fatty acid & Jasminum spp. (Oleaceae), widespread & {$[93,102]$} \\
\hline Phenylethylisothiocyanate & Organosulfur & Brassica spp. (Brassicaceae) & {$[89,103,104]$} \\
\hline Sorbitol & Sugar alcohol & Malus spp. (Rosaceae) & [105] \\
\hline Sulforaphane & Organosulfur & Brassica spp. (Brassicaceae) & {$[106,107]$} \\
\hline \multicolumn{4}{|c|}{ Phenolic Compounds } \\
\hline 2'-Hydroxycinnamaldehyde & Phenolic acid & Cinnamomum spp. (Lauraceae) & {$[108,109]$} \\
\hline 6-Shogaol & Aryl alkanones & Zingiber officinale (Zingiberaceae) & [119] \\
\hline 8-Shogaol & Aryl alkanones & Zingiber officinale (Zingiberaceae) & {$[120]$} \\
\hline Acacetin & Flavone & Robinia pseudoacacia (Fabaceae) & {$[121,122]$} \\
\hline Aesculetin & Coumarin & Aesculus hippocastanum (Hippocastanaceae) & [123] \\
\hline Aloe-emodin & Anthraquinone & Rheum spp. (Polygonaceae), Cassia spp. (Fabaceae) & {$[124,125]$} \\
\hline Apigenin & Flavone & Petroselinum crispum (Apiaceae), widespread & {$[126,127]$} \\
\hline Baicalein & Flavone & $\begin{array}{c}\text { Scutellaria baicalensis (Lamiaceae), Oroxylum indicum } \\
\text { (Bignoniaceae) }\end{array}$ & {$[128,129]$} \\
\hline Baicalin & Flavone & Scutellaria spp. (Lamiaceae) & {$[130,131]$} \\
\hline Benzaldehyde & Aromatic aldehyde & Prunus spp. (Rosaceae), widespread & {$[132,133]$} \\
\hline Betuletol 3-methyl ether & Flavonol & Allagopappus viscosissimus (Asteraceae) & [134] \\
\hline Butein & Chalcone & Rhus verniciflua (Anacardiaceae) & [135] \\
\hline Caffeic acid & Phenolic acid & Coffea spp.(Rubiaceae), widespread & {$[136,137]$} \\
\hline
\end{tabular}


(Table 1) contd....

\begin{tabular}{|c|c|c|c|}
\hline Compound & Type of Compound & Natural Source & References \\
\hline Cajanol & Isoflavanone & Cajanus cajan (Fabaceae) & {$[138]$} \\
\hline Catechin & Flavan-3-ol & Acacia catechu (Fabaceae), widespread & {$[139,140]$} \\
\hline Catechol & Simple phenol & Cola spp. (Malvaceae), Gaultheria spp. (Ericaceae) & {$[141-143]$} \\
\hline Chebulinic acid & Hydrolyzable tannin & Terminalia chebula (Combretaceae) & {$[144,145]$} \\
\hline Chlorogenic acid & Phenolic acid & Coffea spp. (Rubiaceae), widespread & {$[146-148]$} \\
\hline Chrysin & Flavone & Prunus spp. (Rosaceae), & {$[149-151]$} \\
\hline Chrysoeriol & Flavone & Medicago sativa (Fabaceae), widespread & {$[152]$} \\
\hline Chrysophanol & Anthraquinone & $\begin{array}{c}\text { Rhamnus spp. (Rhamnaceae), Rheum spp. (Polygona- } \\
\text { ceae) }\end{array}$ & {$[153]$} \\
\hline Curcumin & Diarylheptanoid & Curcuma longa (Zingiberaceae) & {$[39,154,155]$} \\
\hline Cyanidin & Anthocyanidin & Vaccinium spp. (Ericaceae), Prunus spp. (Rosaceae) & {$[156,157]$} \\
\hline Cyanidin 3-glucoside & Anthocyanin & Vaccinium spp. (Ericaceae), Prunus spp. (Rosaceae) & {$[157,158]$} \\
\hline Cyanidin-3-rutinoside & Anthocyanin & Vaccinium spp. (Ericaceae), Prunus spp. (Rosaceae) & {$[157,159]$} \\
\hline Daidzein & Isoflavone & Glycine max (Fabaceae), widespread & {$[160]$} \\
\hline Dantron & Anthraquinone & Xyris semifuscata (Xyridaceae) & {$[161,162]$} \\
\hline Daphnetin & Coumarin & Daphne spp. (Thymelaeaceae) & {$[163]$} \\
\hline Delphinidin & Anthocyanidin & Delphinium spp. (Ranunculaceae) & {$[157,164]$} \\
\hline Delphinidin 3-sambubioside & Anthocyanin & Hibiscus spp. (Malvaceae) & {$[165]$} \\
\hline Diospyrin & Naphthoquinone & Diospyros montana (Ebenaceae) & {$[166]$} \\
\hline Ellagic acid & Phenolic acid & Vaccinium spp. (Ericaceae), widespread & {$[167]$} \\
\hline Emodin & Anthraquinone & Rheum spp. (Polygonaceae) & {$[168]$} \\
\hline Epicatechin & Flavan-3-ol & Acacia catechu (Fabaceae), widespread & {$[139,169]$} \\
\hline Epicatechin-gallate & Flavan-3-ol & Camellia sinensis (Theaceae) & {$[170]$} \\
\hline Epigallocatechin & Flavan-3-ol & Camellia sinensis (Theaceae) & {$[170]$} \\
\hline Epigallocatechin-3-gallate & Flavan-3-ol & Camellia sinensis (Theaceae) & {$[170,171]$} \\
\hline Eriodictyol & Flavanone & Eriodictyon californicum (Boraginaceae) & {$[172]$} \\
\hline Esculetin (Aesculetin) & Coumarin & Aesculus hippocastanum (Hippocastanaceae) & {$[163,173]$} \\
\hline Eugenol & Phenylpropanoid & Eugenia caryophyllata (Myrtaceae) & {$[174]$} \\
\hline Eupafolin & Flavone & $\begin{array}{l}\text { Eupatorium perfoliatum (Asteraceae), Artemisia prin- } \\
\text { ceps (Asteraceae) }\end{array}$ & {$[175-177]$} \\
\hline Ferulic acid & Phenolic acid & Ferula communis (Apiaceae), widespread & {$[136]$} \\
\hline Fisetin & Flavonol & Fragaria spp. (Rosaceae), widespread & {$[178,179]$} \\
\hline Flavokawain B & Chalcone & Piper methysticum (Piperaceae) & {$[180]$} \\
\hline Fraxetin & Coumarin & Fraxinus spp. (Oleaceae) & {$[173,181]$} \\
\hline Gallic acid & Phenolic acid & Kalanchoe spp. (Crassulaceae), widespread & {$[182,183]$} \\
\hline Gambogic acid & Xanthone & Garcinia hanburyi (Clusiaceae) & {$[184,185]$} \\
\hline
\end{tabular}


(Table 1) contd...

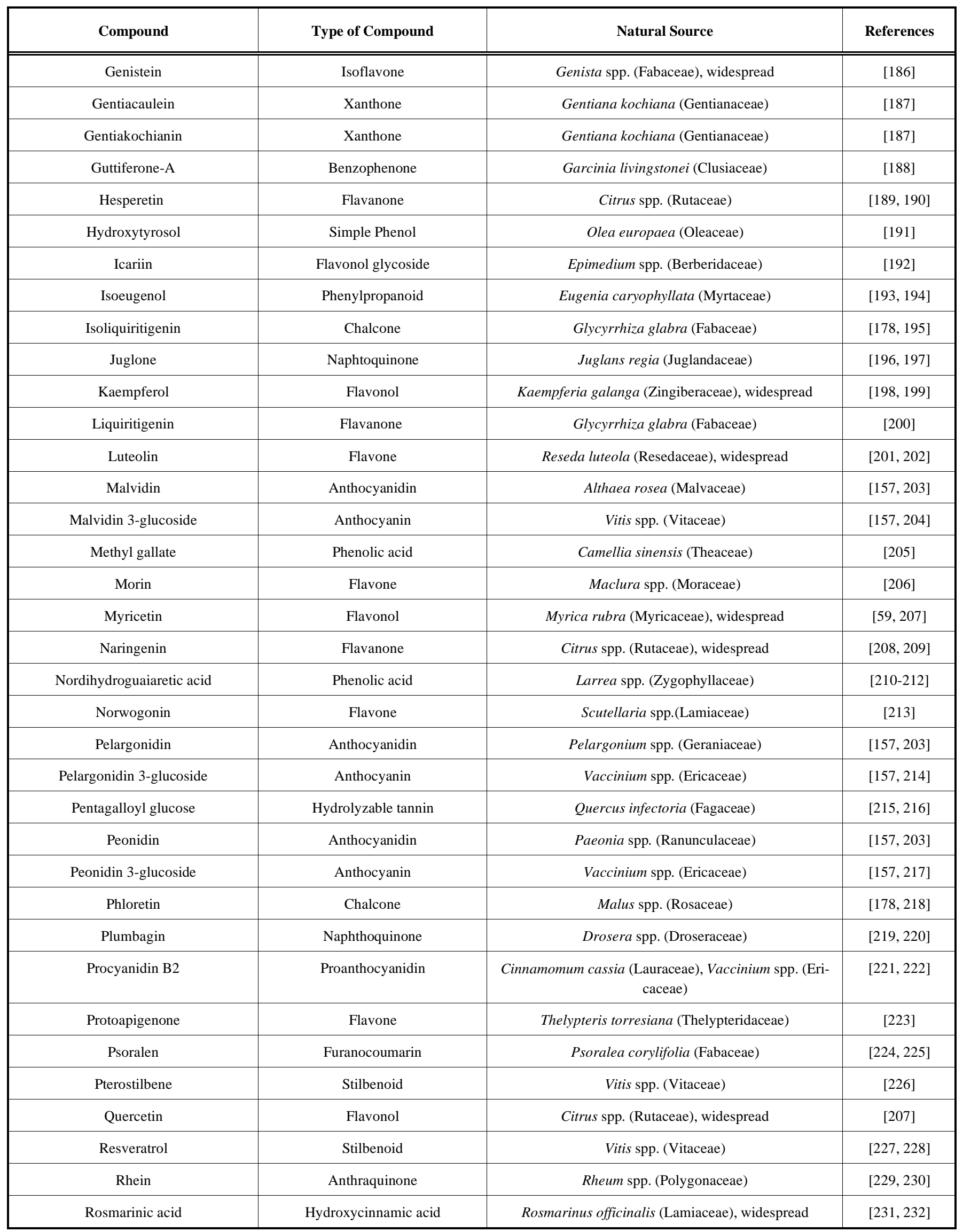


(Table 1) contd....

\begin{tabular}{|c|c|c|c|}
\hline Compound & Type of Compound & Natural Source & References \\
\hline Rottlerin & Phloroglucinol & Mallotus philippinensis (Euphorbiaceae) & {$[233,234]$} \\
\hline Rutin & Flavonol & Ruta spp. (Rutaceae), widespread & {$[235-238]$} \\
\hline Salicylic acid & Phenolic acid & Salix spp. (Salicaceae) & {$[239-241]$} \\
\hline Shikonin & Naphthoquinone & Lithospermum erythrorhizon (Boraginaceae) & {$[242,243]$} \\
\hline Sinapic acid & Phenolic acid & Brassica spp.(Brassicaceae), widespread & {$[113,114]$} \\
\hline Sophoranone & Flavanone & Sophora subprostrata (Fabaceae) & {$[244]$} \\
\hline Tannic acid & Tannin & Quercus spp. (Fagaceae), widespread & {$[245,246]$} \\
\hline Taxifolin & Flavanonol & Silybum marianum (Asteraceae) & {$[111,149,247]$} \\
\hline Tricetin & Flavone & Oryza sativa (Poaceae) & {$[248]$} \\
\hline Usnic acid & Dibenzofuran & Usnea spp. (Parmeliaceae) & {$[249,250]$} \\
\hline Vanillin & Phenolic acid & Vanilla spp. (Orchidaceae) & {$[251-253]$} \\
\hline Wogonin & Flavone & Scutellaria baicalensis (Lamiaceae) & {$[254,255]$} \\
\hline Xanthohumol & Chalcone & Humulus lupulus (Cannabaceae) & {$[256,257]$} \\
\hline Xanthotoxin & Furanocoumarin & Ammi majus (Apiaceae) & {$[258,259]$} \\
\hline \multicolumn{4}{|c|}{ Terpenoids } \\
\hline 18ß-Glycyrrhetinic acid & Triterpenoid & Glycyrrhiza glabra (Fabaceae) & {$[260,261]$} \\
\hline Andrographolide & Diterpenoid & Andrographis paniculata (Acanthaceae) & {$[262]$} \\
\hline Artemisinin & Lactone sesquiterpenoid & Artemisia annua (Asteraceae) & {$[263-265]$} \\
\hline Asiatic acid & Triterpenoid & Centella asiatica (Mackinlayaceae) & {$[266]$} \\
\hline Astilbotriterpenic acid & Triterpenoid & Astilbe chinensis (Saxifragaceae) & {$[267]$} \\
\hline Betulinic acid & Triterpenoid & Betula spp. (Betulaceae) & {$[268]$} \\
\hline Bixin & Apocarotenoid & Bixa orellana (Bixaceae) & {$[269]$} \\
\hline Bufalin & Cardiac glycoside & Bufo bufo (Bufonidae) & {$[270]$} \\
\hline Cannabidiol & Cannabinoid & Cannabis sativa (Cannabaceae) & {$[271-273]$} \\
\hline Costunolide & Sesquiterpenoid & Laurus nobilis (Lauraceae) & {$[274,275]$} \\
\hline Cucurbitacin B & Triterpenoid & Iberis amara (Brassicaceae) & {$[276]$} \\
\hline Dioscin & Steroidal saponin & Dioscorea spp. (Dioscoreaceae) & {$[277]$} \\
\hline Diosgenin & Steroidal sapogenin & Dioscorea spp. (Dioscoreaceae) & {$[278]$} \\
\hline Erythrodiol & Triterpenoid & Olea europaea (Oleaceae) & {$[279,280]$} \\
\hline Farnesol & Sesquiterpenoid & Vachellia farnesiana (Fabaceae), widespread & {$[281-283]$} \\
\hline Ginkgolide B & Diterpenoid & Ginkgo biloba (Ginkgoaceae) & {$[284,285]$} \\
\hline Ginsenoside RH-2 & Triterpenoid saponin & Ginkgo biloba (Ginkgoaceae) & {$[286,287]$} \\
\hline Glaucocalyxin A & Diterpenoid & Rabdosia japonica var. glaucocalyx (Lamiaceae) & {$[288]$} \\
\hline Guggulsterone & Triterpenoid & Commiphora mukul (Burseraceae) & {$[289,290]$} \\
\hline Gypenosides & Triterpenoid & Gynostemma pentaphyllum (Cucurbitaceae) & {$[291,292]$} \\
\hline Helenalin & Sesquiterpenoid & Arnica spp. (Asteraceae) & {$[293]$} \\
\hline Linalool & Monoterpenoid & Coriandrum sativum (Apiaceae), widespread & {$[294]$} \\
\hline
\end{tabular}


(Table 1) contd....

\begin{tabular}{|c|c|c|c|}
\hline Compound & Type of Compound & Natural Source & References \\
\hline Lupeol & Triterpenoid & Mangifera spp. (Anacardiaceae), widespread & [295] \\
\hline Lycopene & Carotenoid & Solanum lycopersicum (Solanaceae) & [296-298] \\
\hline Oleandrin & Cardiac glycoside & Nerium oleander (Apocynaceae) & [299] \\
\hline Oleanolic acid & Triterpenoid & Olea europaea (Oleaceae), widespread & {$[300,301]$} \\
\hline Oleuropein & Iridoid & Olea europaea (Oleaceae) & [302-304] \\
\hline Oridonin & Diterpenoid & Rabdosia rubescens (Lamiaceae) & [305] \\
\hline Ouabain & Cardiac glycoside & Strophanthus gratus, S. kombe (Apocynaceae) & [306] \\
\hline Ovatodiolide & Diterpenoid & Anisomeles indica (Lamiaceae) & [307] \\
\hline Taxol & Diterpenoid & Taxus brevifolia (Taxaceae) & {$[6,308,309]$} \\
\hline Parthenolide & Sesquiterpenoid & Chrysanthemum parthenium (Asteraceae) & {$[310,311]$} \\
\hline Perillyl alcohol & Monoterpenoid & Perilla frutescens (Lamiaceae) & {$[312,313]$} \\
\hline Polygodial & Sesquiterpenoid & Tasmannia spp. (Winteraceae) & {$[314,315]$} \\
\hline Pristimerin & Triterpenoid & Maytenus heterophylla (Celastraceae) & {$[316,317]$} \\
\hline Protopanaxadiol & Triterpenoid saponin & Panax ginseng (Araliaceae) & {$[318,319]$} \\
\hline Sarsasapogenin & Steroidal sapogenin & Smilax spp. (Smilacaceae) & [320] \\
\hline Tetrahydrocannabinol & Cannabinoid & Cannabis sativa (Cannabaceae) & [321] \\
\hline Thymol & Monoterpenoid & Thymus spp. (Lamiaceae), widespread & [322] \\
\hline Triptolide & Diterpenoid & Tripterygium wilfordii (Celastraceae) & {$[323,324]$} \\
\hline Ursolic acid & Triterpenoid & Arctostaphylos uva-ursi (Ericaceae), widespread & [325] \\
\hline Uvaol & Triterpenoid & Olea europaea (Oleaceae) & [280] \\
\hline Withaferin & Withasteroid & Withania somnifera (Solanaceae) & {$[326,327]$} \\
\hline$\alpha$-Hederin & Triterpenoid saponin & Hedera helix (Araliaceae) & [328] \\
\hline$\alpha$-humulene & Sesquiterpenoid & Humulus lupulus (Cannabaceae) & [329] \\
\hline$\beta$-Amyrin & Triterpenoid & Medicago sativa (Fabaceae), widespread & [330] \\
\hline$\beta$-carotene & Carotenoid & Daucus carota (Apiaceae), widespread & [331-333] \\
\hline$\beta$-Escin (aescin) & Triterpenoid saponin & Aesculus hippocastanum (Hippocastanaceae) & [334] \\
\hline Atractyloside & Diterpenoid & Atractylis spp. (Asteraceae) & {$[335,336]$} \\
\hline$\beta$-Sitosterol & Phytosterol & Serenoa repens (Arecaceae), widespread & [337] \\
\hline Vernolepin & Lactone sesquiterpenoid & Vernonia hymenolepis (Compositae) & [338] \\
\hline \multicolumn{4}{|c|}{ Alkaloids } \\
\hline 6-Methoxydihydrosanguinarine & Benzophenanthridine & Hylomecon hylomeconoides (Papaveraceae) & {$[339,340]$} \\
\hline Berberine & Isoquinoline & Berberis spp. (Berberidaceae) & {$[341,342]$} \\
\hline Boldine & Aporphine & Peumus boldus (Monimiaceae) & {$[343,344]$} \\
\hline Caffeine & Xanthine & $\begin{array}{c}\text { Coffea spp. (Rubiaceae), Camellia sinensis } \\
\text { (Theaceae) }\end{array}$ & [345-347] \\
\hline Camptothecin & Quinoline & Camptotheca acuminata (Nyssaceae) & {$[7,348]$} \\
\hline Cepharanthine & Isoquinoline & Stephania cepharantha (Menispermaceae) & {$[349,350]$} \\
\hline
\end{tabular}


(Table 1) contd....

\begin{tabular}{|c|c|c|c|}
\hline Compound & Type of Compound & Natural Source & References \\
\hline Chelerythrine & Phenanthridine & Chelidonium majus (Papaveraceae) & {$[351-353]$} \\
\hline Ellipticine & Pyridocarbazole & Ochrosia elliptica (Apocynaceae) & {$[354-356]$} \\
\hline Homoharringtonine & Cephalotaxine & Cephalotaxus harringtonia (Cephalotaxaceae) & {$[357]$} \\
\hline Indole acetic acid & Indole & Arabidopsis thaliana (Brassicaceae) & {$[358,359]$} \\
\hline Indole-3-carbinol & Indole & Brassica spp. (Brassicaceae) & {$[360]$} \\
\hline Lycopodine & Quinolizidine & Lycopodium clavatum (Lycopodiaceae) & {$[361]$} \\
\hline Morphine & Phenanthrene & Papaver somniferum (Papaveraceae) & {$[362,363]$} \\
\hline Oxymatrine & Quinolizidine & Sophora flavescens (Fabaceae) & {$[364]$} \\
\hline Pancratistatin & Phenanthridine & Hymenocallis spp. (Amaryllidaceae) & {$[365,366]$} \\
\hline Piperine & Piperidine & Piper spp. (Piperaceae) & {$[367,368]$} \\
\hline Sampangine & Aporphine & Cananga odorata (Annonaceae) & {$[369]$} \\
\hline Sanguinarine & Benzylisoquinoline & Sanguinaria canadensis (Papaveraceae) & {$[353,370]$} \\
\hline Tetrandrine & Bis-benzylisoquinoline & Stephania tetrandra (Menispermaceae) & {$[371,372]$} \\
\hline Tomatine & Steroidal & Solanum lycopersicum (Solanaceae) & {$[373,374]$} \\
\hline Vinblastine & Bis-indole & Catharanthus roseus (Apocynaceae) & {$[375,376]$} \\
\hline Vincristine & Bis-indole & Catharanthus roseus (Apocynaceae) & {$[377,378]$} \\
\hline \multicolumn{4}{|c|}{ Other Natural Products } \\
\hline $\begin{array}{l}\text { 4-Acetyl-12,13-epoxyl-9- } \\
\text { trichothecene-3,15-diol }\end{array}$ & Macrocyclic Trichocenes & Isaria japonica (Onygenaceae) & {$[379]$} \\
\hline Aclarubicin & anthracycline & Streptomyces galilaeus (Streptomycetaceae) & {$[380]$} \\
\hline Actinomycin-D & Polypeptide & Streptomyces spp. (Streptomycetaceae) & {$[381,382]$} \\
\hline Aplidin & Depsipeptide & Aplidium albicans (Clavelinidae) & {$[383-385]$} \\
\hline Arachidonic acid & Fatty acid & Widespread in vertebrates & {$[96,386,387]$} \\
\hline Ascididemin & Pyridoacridine & Cystodytes dellechiajei (Polycitoridae) & {$[388,389]$} \\
\hline Bleomycin & Glucopeptide & Streptomyces verticillus (Streptomycetaceae) & {$[390,391]$} \\
\hline Boningmycin & Glucopeptide & $\begin{array}{c}\text { Streptomyces verticillus var. pingyangensis (Streptomy- } \\
\text { cetaceae) }\end{array}$ & {$[392]$} \\
\hline Butenolide & Lactone & Angelica spp. (Apiaceae) & {$[393]$} \\
\hline Capsaicin & Capsaicinoid & Capsicum spp. (Solanaceae) & {$[394,395]$} \\
\hline Chenodeoxycholic acid & Bile acid & Liver of animals & {$[396-398]$} \\
\hline Cholic acid & Bile acid & Liver of animals & {$[399,400]$} \\
\hline C-phycocyanin & Phycobiliprotein & Aphanizomenon flos-aquae (Nostocaceae) & {$[401]$} \\
\hline Cribrostatin 6 & Quinone & Cribrochalina spp. (Haliclonidae) & {$[402]$} \\
\hline Daunomycin & anthracycline & Streptomyces peucetius (Streptomycetaceae) & {$[403]$} \\
\hline Deoxycholic acid & Bile acid & Liver of animals & {$[397,398,404]$} \\
\hline Deoxynivalenol (Vomitoxin) & Epoxy-sesquiterpenoid & Fusarium spp. (Nectriaceae) & {$[405,406]$} \\
\hline Docosahexaenoic acid (DHA) & Fatty acid & Crypthecodinium cohnii, Schizochytrium spp. & [407] \\
\hline
\end{tabular}


(Table 1) contd....

\begin{tabular}{|c|c|c|c|}
\hline Compound & Type of Compound & Natural Source & References \\
\hline Doxorubicin & Anthracycline & Streptomyces spp. (Streptomycetaceae) & {$[377,408,409]$} \\
\hline Eicosapentaenoic acid (EPA) & Fatty acid & Crypthecodinium cohnii, Parietochloris incise & {$[96,410,411]$} \\
\hline F-2 Mycotoxin (Zearalenone) & Trichothecene & Gibberella spp. (Nectriaceae) & {$[412,413]$} \\
\hline Fucoxanthin & Carotenoid & Undaria pinnatifida (Alariaceae) & {$[414]$} \\
\hline Isoobtusilactone A & Butanolide & Cinnamomum kotoense (Lauraceae) & {$[415,416]$} \\
\hline Kotomolide A & Butyrolactone & Cinnamomum kotoense (Lauraceae) & {$[417]$} \\
\hline Mitomycin C & Aziridine & Streptomyces caespitosus (Streptomycetaceae) & {$[418-420]$} \\
\hline Neocarzinostatin & chromoprotein enediyne & Streptomyces carzinostaticus (Streptomycetaceae) & {$[421]$} \\
\hline Norharman & $\beta$-carboline alkaloid & Passiflora incarnata (Passifloraceae) & {$[422,423]$} \\
\hline Ochratoxin A & Pentaketide & Aspergillus ochraceus (Trichocomaceae) & [424-426] \\
\hline Patulin & Furopyranone & Penicillium spp. (Trichocomaceae) & {$[427-429]$} \\
\hline Putrescine-1,4-dicinnamide & Phenylpropanoid & Pholiota spumosa (Strophariaceae) & {$[430]$} \\
\hline Secotenuifolide & Butanolide & Cinnamomum tenuifolium (Lauraceae) & {$[431]$} \\
\hline $\mathrm{T}-2$ mycotoxin & Trichothecene & Fusarium spp. (Nectriaceae) & {$[432,433]$} \\
\hline Ursodeoxycholic acid & Bile acid & Liver of animals & {$[434]$} \\
\hline Vitamin A (retinol) & Carotenoid & Daucus carota (Apiaceae) & {$[435-437]$} \\
\hline Vitamin C (Ascorbic acid) & Butenolide & Citrus spp. (Rutaceae), widespread & {$[56,438,439]$} \\
\hline Vitamin D2 (Ergocalciferol) & Steroid & Lentinus edodes (Marasmiaceae) & {$[440]$} \\
\hline Vitamin D3 (Cholecalciferol) & Steroid & Animal origin & {$[441,442]$} \\
\hline Vitamin $\mathrm{K} 2$ & Naftoquinone & Brassica spp. (Brassicaceae), widespread & {$[443,444]$} \\
\hline Vitamin $\mathrm{K} 3$ & Naftoquinone & Brassica spp. (Brassicaceae), widespread & {$[445,446]$} \\
\hline
\end{tabular}
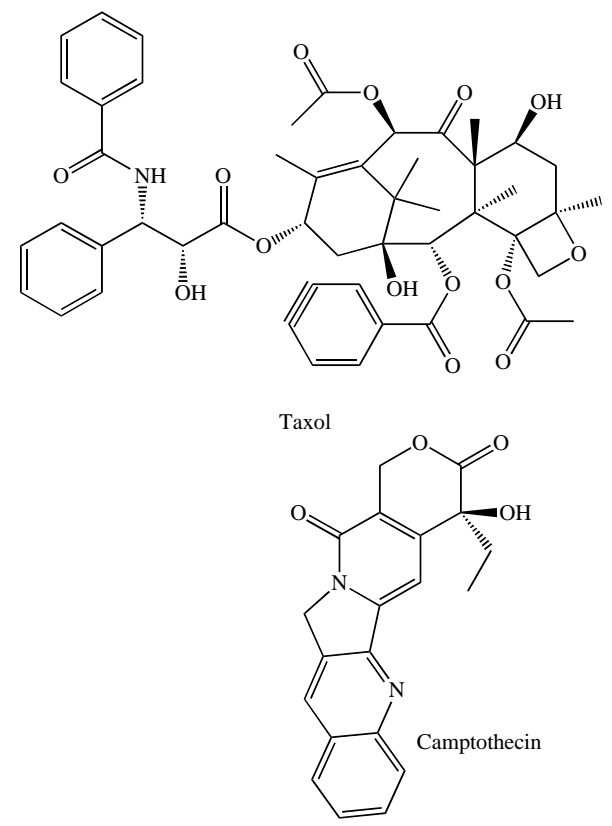

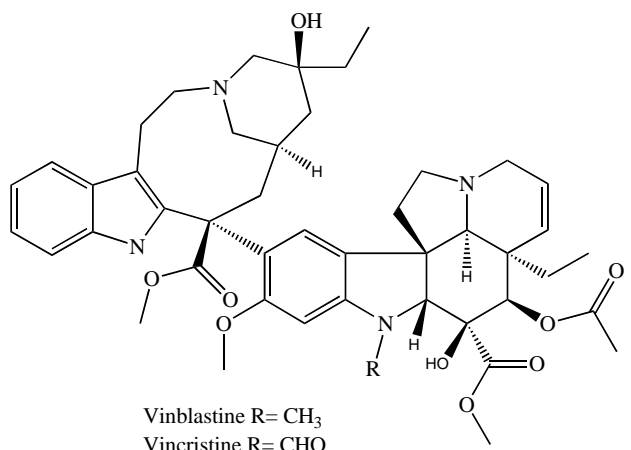

Vincristine $\mathrm{R}=\mathrm{CHO}$<smiles>O=c1c(-c2ccc(O)cc2)coc2cc(O)cc(O)c12</smiles> 

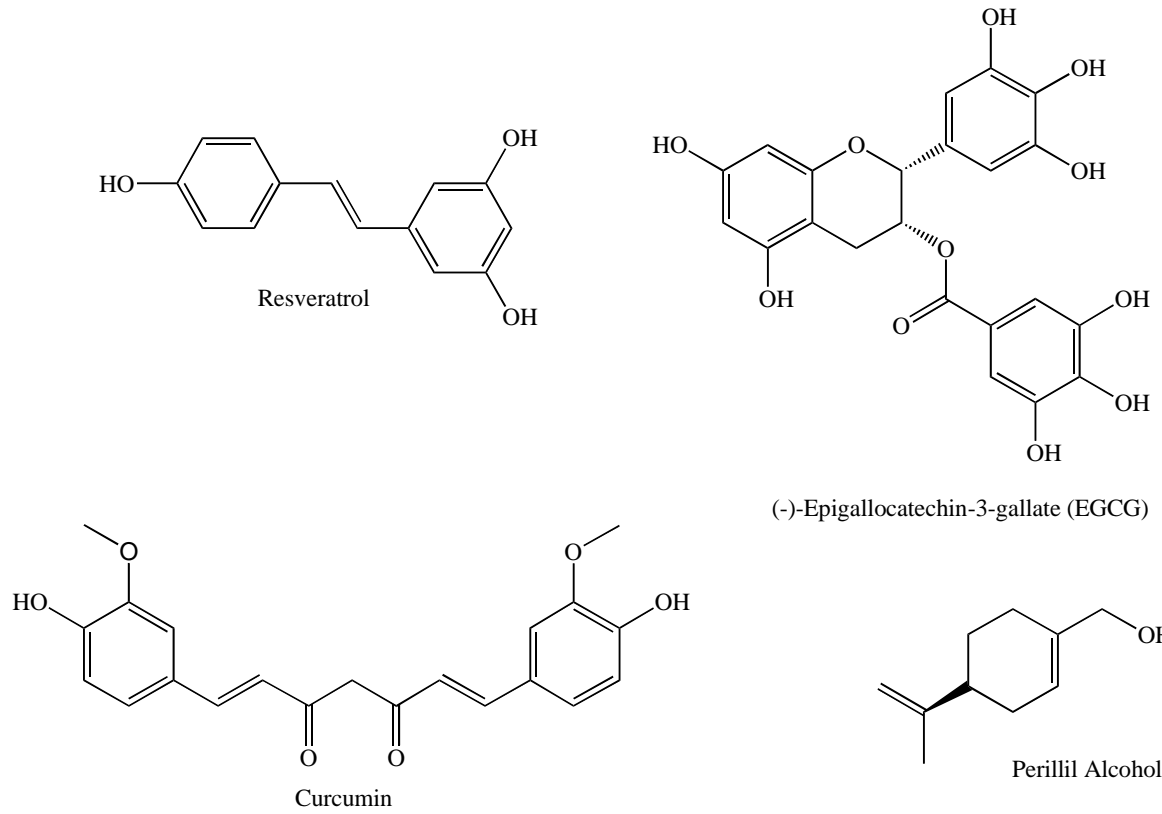

(-)-Epigallocatechin-3-gallate (EGCG)<smiles>C=C(C)[C@H]1CC=C(CO)CC1</smiles><smiles>CC(C)=CCC/C(C)=C/C=C/C(C)=C/C=C/C(C)=C/C=C/C=C(C)/C=C/C=C(C)/C=C/C=C(\C)CCC=C(C)C</smiles>

Fig. (1). Selected plant secondary metabolites with pro-oxidant and anticancer activities.

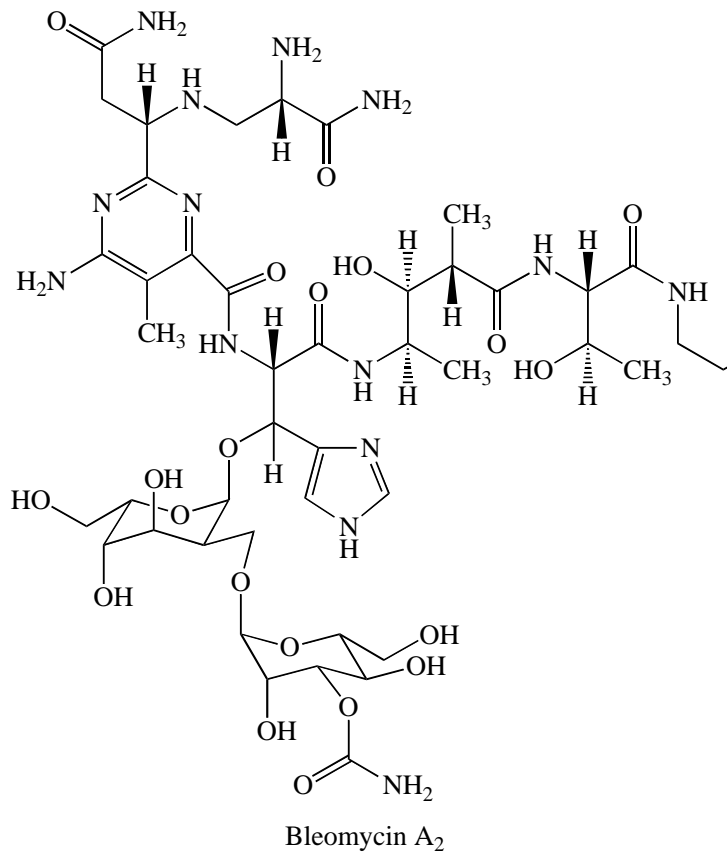<smiles>Cc1cc2c(c(O)c1C)C(=O)c1c(O)cccc1C2=O</smiles><smiles>CCOC=[Pb]</smiles><smiles>COc1cccc2c1C(=O)c1c(O)c3c(c(O)c1C2=O)C[C@@](O)(C(C)=O)C[C@@H]3O[C@H]1C[C@H](N)[C@@H](O)[C@H](C)O1</smiles>

Bleomycin $\mathrm{A}_{2}$ 
(Fig. 2) contd...

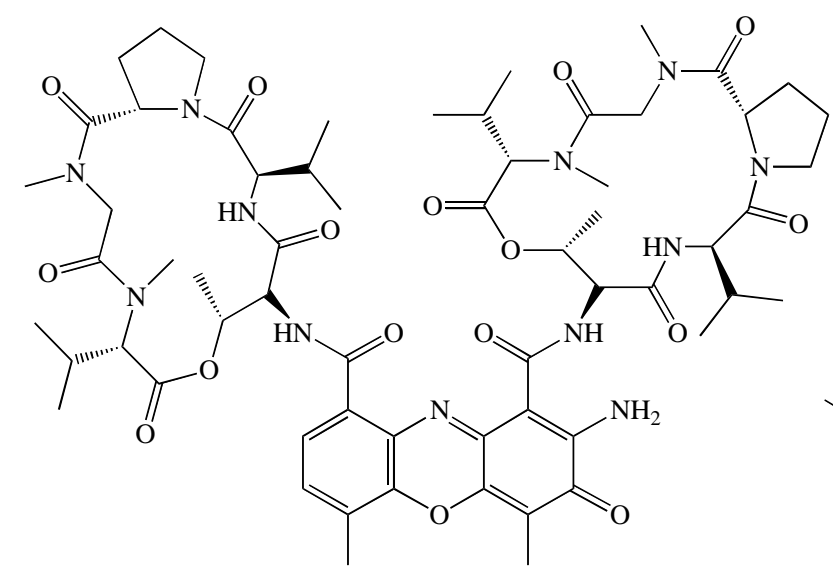<smiles>CCCCCCN=C=S=[W]</smiles>

Actinomycin D
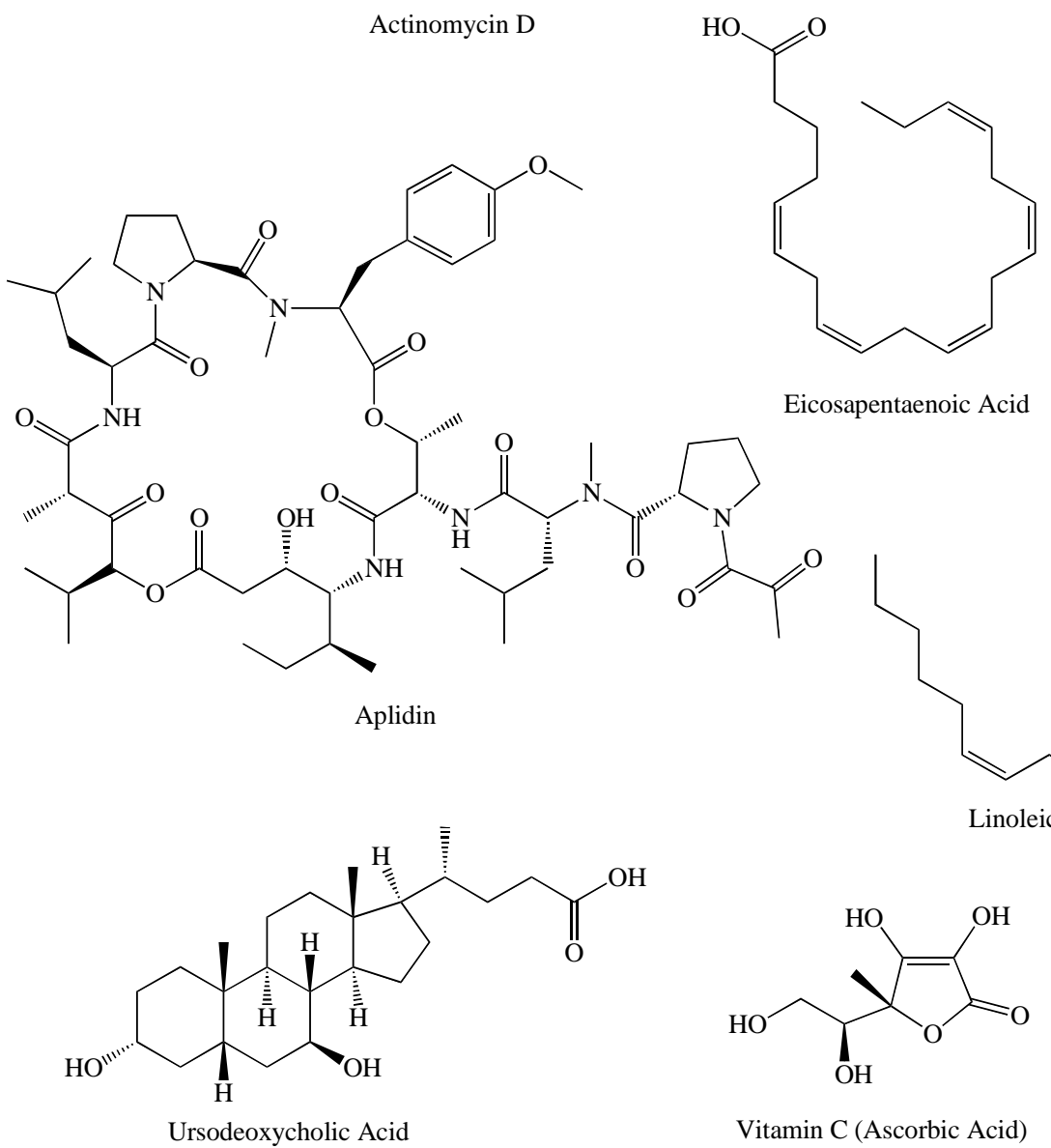<smiles>CO[C@]12[C@H](COC(N)=O)C3=C(C(=O)C(C)=C(N)C3=O)N1C[C@@H]1N[C@H]12</smiles>

Eicosapentaenoic Acid

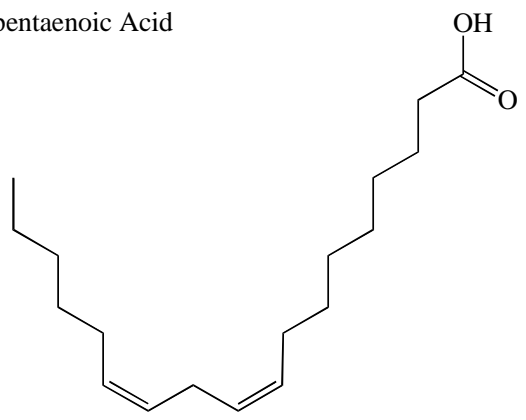

Phenylethyl isothiocyanate

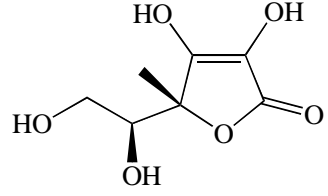

Vitamin C (Ascorbic Acid)

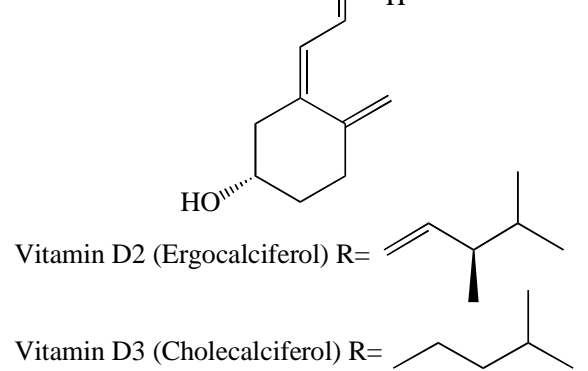

Fig. (2). Selected natural products, excluding plant secondary metabolites, with pro-oxidant and anticancer activities.

vate, which is an efficient scavenger of $\mathrm{H}_{2} \mathrm{O}_{2}$ [75-78]. Second, glucose metabolism through the pentose phosphate pathway regenerates NADPH from $\mathrm{NADP}^{+}$in a reaction in which glucose-6-phosphate is converted into 6phosphogluconolactone by the enzyme glucose-6-phosphate dehydrogenase. The regeneration of NADPH is required for $\mathrm{H}_{2} \mathrm{O}_{2}$ detoxification through the glutathione peroxidase/glutathione reductase system and through the thioredoxin peroxidase/thioredoxin reductase system [73, 79, 80] (reviewed in [13]). Therefore, the anticancer potential of pro- oxidant natural products could be maximized in combination with glycolysis inhibitors.

In conclusion, natural products have made a significant contribution to the development of many anticancer drugs currently used in chemotherapy. Recent observations suggest that pro-oxidant agents may represent a new class of anticancer drugs with capacity to target tumor cells selectively. In this article, we have provided an overview of pro-oxidant natural products with anticancer activity and discussed their anticancer potential. 


\section{CONFLICT OF INTEREST}

Declared none.

\section{ACKNOWLEDGEMENT}

Declared none.

\section{REFERENCES}

[1] Jemal A, Bray F, Center MM, Ferlay J, Ward E, Forman D. Global cancer statistics. CA Cancer J Clin 2011; 61: 69-90.

[2] Jemal A, Siegel R, Xu J, Ward E. Cancer statistics, 2010. CA Cancer J Clin 2010; 60: 277-300.

[3] Newman DJ, Cragg GM. Natural products as sources of new drugs over the last 25 years. J Nat Prod 2007; 70: 461-77.

[4] Cragg GM, Grothaus PG, Newman DJ. Impact of natural products on developing new anti-cancer agents. Chem Rev 2009; 109: 301243

[5] Cragg GM, Newman DJ. Plants as a source of anti-cancer agents. J Ethnopharmacol 2005; 100: 72-9.

[6] Alexandre J, Batteux F, Nicco C, et al. Accumulation of hydrogen peroxide is an early and crucial step for paclitaxel-induced cancer cell death both in vitro and in vivo. Int J Cancer 2006; 119: 41-8.

[7] Gorman A, McGowan A, Cotter TG. Role of peroxide and superoxide anion during tumour cell apoptosis. FEBS Lett 1997; 404: 27-33.

[8] Alexandre J, Hu Y, Lu W, Pelicano H, Huang P. Novel action of paclitaxel against cancer cells: bystander effect mediated by reactive oxygen species. Cancer Res 2007; 67: 3512-7.

[9] Pelicano H, Carney D, Huang P. ROS stress in cancer cells and therapeutic implications. Drug Resist Updat 2004; 7: 97-110.

[10] Renschler MF. The emerging role of reactive oxygen species in cancer therapy. Eur J Cancer 2004; 40: 1934-40.

[11] Schumacker PT. Reactive oxygen species in cancer cells: live by the sword, die by the sword. Cancer Cell 2006; 10: 175-6.

[12] Lopez-Lazaro M. Dual role of hydrogen peroxide in cancer: Possible relevance to cancer chemoprevention and therapy. Cancer Lett 2007; 252: 1-8

[13] Lopez-Lazaro M. A new view of carcinogenesis and an alternative approach to cancer therapy. Mol Med 2010; 16: 144-53.

[14] Halliwell B. Free radicals and antioxidants - quo vadis? Trends Pharmacol Sci 2011; 32: 125-30.

[15] Droge W. Free radicals in the physiological control of cell function. Physiol Rev 2002; 82: 47-95.

[16] Balaban RS, Nemoto S, Finkel T. Mitochondria, oxidants, and aging. Cell 2005; 120: 483-95.

[17] Szatrowski TP, Nathan CF. Production of large amounts of hydrogen peroxide by human tumor cells. Cancer Res 1991; 51: 794-8

[18] Halliwell B. Oxidative stress and cancer: have we moved forward? Biochem J 2007; 401: 1-11.

[19] Kovacic P, Jacintho JD. Mechanisms of carcinogenesis: focus on oxidative stress and electron transfer. Curr Med Chem 2001; 8: 773-96.

[20] Lopez-Lazaro M. Role of oxygen in cancer: looking beyond hypoxia. Anticancer Agents Med Chem 2009; 9: 517-25.

[21] Lopez-Lazaro M. Excessive superoxide anion generation plays a key role in carcinogenesis. Int J Cancer 2007; 120: 1378-80.

[22] Okamoto M, Kawai K, Reznikoff CA, Oyasu R. Transformation in vitro of a nontumorigenic rat urothelial cell line by hydrogen peroxide. Cancer Res 1996; 56: 4649-53.

[23] Suh YA, Arnold RS, Lassegue B, et al. Cell transformation by the superoxide-generating oxidase Mox1. Nature 1999; 401: 79-82.

[24] Arnold RS, Shi J, Murad E, et al. Hydrogen peroxide mediates the cell growth and transformation caused by the mitogenic oxidase Nox1. Proc Natl Acad Sci USA 2001; 98: 5550-5.

[25] Vogelstein B, Kinzler KW. Cancer genes and the pathways they control. Nat Med 2004; 10: 789-99.

[26] Hanahan D, Weinberg RA. The hallmarks of cancer. Cell 2000; 100: 57-70.

[27] Hahn WC, Weinberg RA. Rules for making human tumor cells. N Engl J Med 2002; 347: 1593-603.
[28] Park S, You X, Imlay JA. Substantial DNA damage from submicromolar intracellular hydrogen peroxide detected in Hpx- mutants of Escherichia coli. Proc Natl Acad Sci USA 2005; 102: 9317-22.

[29] Henle ES, Linn S. Formation, prevention, and repair of DNA damage by iron/hydrogen peroxide. J Biol Chem 1997; 272: 19095-8.

[30] Hunt CR, Sim JE, Sullivan SJ, et al. Genomic instability and catalase gene amplification induced by chronic exposure to oxidative stress. Cancer Res 1998; 58: 3986-92.

[31] Burdon RH. Superoxide and hydrogen peroxide in relation to mammalian cell proliferation. Free Radic Biol Med 1995; 18: 77594.

[32] Brown MR, Miller FJ, Jr., Li WG, et al. Overexpression of human catalase inhibits proliferation and promotes apoptosis in vascular smooth muscle cells. Circ Res 1999; 85: 524-33.

[33] del Bello B, Paolicchi A, Comporti M, Pompella A, Maellaro E. Hydrogen peroxide produced during gamma-glutamyl transpeptidase activity is involved in prevention of apoptosis and maintainance of proliferation in U937 cells. FASEB J 1999; 13: 69-79.

[34] Qian Y, Luo J, Leonard SS, et al. Hydrogen peroxide formation and actin filament reorganization by $\mathrm{Cdc} 42$ are essential for ethanol-induced in vitro angiogenesis. J Biol Chem 2003; 278: 1618997.

[35] Arbiser JL, Petros J, Klafter R, et al. Reactive oxygen generated by Nox1 triggers the angiogenic switch. Proc Natl Acad Sci USA 2002; 99: 715-20.

[36] Polytarchou C, Hatziapostolou M, Papadimitriou E. Hydrogen peroxide stimulates proliferation and migration of human prostate cancer cells through activation of activator protein-1 and upregulation of the heparin affin regulatory peptide gene. J Biol Chem 2005; 280: 40428-35.

[37] Nelson KK, Ranganathan AC, Mansouri J, et al. Elevated sod2 activity augments matrix metalloproteinase expression: evidence for the involvement of endogenous hydrogen peroxide in regulating metastasis. Clin Cancer Res 2003; 9: 424-32.

[38] Nishikawa M, Tamada A, Hyoudou K, et al. Inhibition of experimental hepatic metastasis by targeted delivery of catalase in mice. Clin Exp Metastasis 2004; 21: 213-21.

[39] Lopez-Lazaro M. Anticancer and carcinogenic properties of curcumin: considerations for its clinical development as a cancer chemopreventive and chemotherapeutic agent. Mol Nutr Food Res 2008; 52 Suppl 1: S103-27.

[40] Fang J, Nakamura H, Iyer AK. Tumor-targeted induction of oxystress for cancer therapy. J Drug Target 2007; 15: 475-86.

[41] Fruehauf JP, Meyskens FL, Jr. Reactive oxygen species: a breath of life or death? Clin Cancer Res 2007; 13: 789-94.

[42] Wondrak GT. Redox-directed cancer therapeutics: molecular mechanisms and opportunities. Antioxid Redox Signal 2009; 11: 3013-69.

[43] Engel RH, Evens AM. Oxidative stress and apoptosis: a new treatment paradigm in cancer. Front Biosci 2006; 11:300-12.

[44] Alexandre J, Nicco C, Chereau C, et al. Improvement of the therapeutic index of anticancer drugs by the superoxide dismutase mimic mangafodipir. J Natl Cancer Inst 2006; 98: 236-44.

[45] Jing Y, Dai J, Chalmers-Redman RM, Tatton WG, Waxman S Arsenic trioxide selectively induces acute promyelocytic leukemia cell apoptosis via a hydrogen peroxide-dependent pathway. Blood 1999; 94: 2102-11.

[46] Mizutani H, Tada-Oikawa S, Hiraku Y, Kojima M, Kawanishi S. Mechanism of apoptosis induced by doxorubicin through the generation of hydrogen peroxide. Life Sci 2005; 76: 1439-53.

[47] Ubezio P, Civoli F. Flow cytometric detection of hydrogen peroxide production induced by doxorubicin in cancer cells. Free Radic Biol Med 1994; 16: 509-16.

[48] Ikeda K, Kajiwara K, Tanabe E, et al. Involvement of hydrogen peroxide and hydroxyl radical in chemically induced apoptosis of HL-60 cells. Biochem Pharmacol 1999; 57: 1361-5.

[49] Simizu S, Takada M, Umezawa K, Imoto M. Requirement of caspase-3(-like) protease-mediated hydrogen peroxide production for apoptosis induced by various anticancer drugs. J Biol Chem 1998; 273: 26900-7.

[50] Ling YH, Liebes L, Zou Y, Perez-Soler R. Reactive oxygen species generation and mitochondrial dysfunction in the apoptotic response to Bortezomib, a novel proteasome inhibitor, in human $\mathrm{H} 460$ nonsmall cell lung cancer cells. J Biol Chem 2003; 278: 33714-23. 
[51] Perez-Galan P, Roue G, Villamor N, Montserrat E, Campo E, Colomer D. The proteasome inhibitor bortezomib induces apoptosis in mantle-cell lymphoma through generation of ROS and Noxa activation independent of p53 status. Blood 2006; 107: 257-64.

[52] Oh SY, Sohn YW, Park JW, et al. Selective cell death of oncogenic Akt-transduced brain cancer cells by etoposide through reactive oxygen species mediated damage. Mol Cancer Ther 2007; 6: 217887.

[53] Doroshow JH. Role of hydrogen peroxide and hydroxyl radical formation in the killing of Ehrlich tumor cells by anticancer quinones. Proc Natl Acad Sci USA 1986; 83: 4514-8.

[54] Geng CX, Zeng ZC, Wang JY. Docetaxel inhibits SMMC-7721 human hepatocellular carcinoma cells growth and induces apoptosis. World J Gastroenterol 2003; 9: 696-700.

[55] Hirpara JL, Clement MV, Pervaiz S. Intracellular acidification triggered by mitochondrial-derived hydrogen peroxide is an effector mechanism for drug-induced apoptosis in tumor cells. J Biol Chem 2001; 276: 514-21.

[56] Chen Q, Espey MG, Krishna MC, et al. Pharmacologic ascorbic acid concentrations selectively kill cancer cells: action as a prodrug to deliver hydrogen peroxide to tissues. Proc Natl Acad Sci USA 2005 ; 102: 13604-9.

[57] Maeda H, Hori S, Ohizumi H, et al. Effective treatment of advanced solid tumors by the combination of arsenic trioxide and Lbuthionine-sulfoximine. Cell Death Differ 2004; 11: 737-46.

[58] Djavaheri-Mergny M, Wietzerbin J, Besancon F. 2Methoxyestradiol induces apoptosis in Ewing sarcoma cells through mitochondrial hydrogen peroxide production. Oncogene 2003; 22: 2558-67.

[59] Lopez-Lazaro M, Calderon-Montano JM, Burgos-Moron E, Austin CA. Green tea constituents (-)-epigallocatechin-3-gallate (EGCG) and gallic acid induce topoisomerase I- and topoisomerase II-DNA complexes in cells mediated by pyrogallol-induced hydrogen peroxide. Mutagenesis 2011; 26: 489-98.

[60] Zieba M, Suwalski M, Kwiatkowska S, et al. Comparison of hydrogen peroxide generation and the content of lipid peroxidation products in lung cancer tissue and pulmonary parenchyma. Respir Med 2000; 94: 800-5.

[61] Lim SD, Sun C, Lambeth JD, et al. Increased Nox1 and hydrogen peroxide in prostate cancer. Prostate 2005; 62: 200-7.

[62] Aykin-Burns N, Ahmad IM, Zhu Y, Oberley LW, Spitz DR. Increased levels of superoxide and $\mathrm{H} 2 \mathrm{O} 2$ mediate the differential susceptibility of cancer cells versus normal cells to glucose deprivation. Biochem J 2009; 418: 29-37.

[63] Helleday T, Petermann E, Lundin C, Hodgson B, Sharma RA. DNA repair pathways as targets for cancer therapy. Nat Rev Cancer 2008; 8: 193-204.

[64] Hadi SM, Bhat SH, Azmi AS, Hanif S, Shamim U, Ullah MF. Oxidative breakage of cellular DNA by plant polyphenols: a putative mechanism for anticancer properties. Semin Cancer Biol 2007; 17: 370-6.

[65] Estrela JM, Ortega A, Obrador E. Glutathione in cancer biology and therapy. Crit Rev Clin Lab Sci 2006; 43: 143-81.

[66] Tew KD. Glutathione-associated enzymes in anticancer drug resistance. Cancer Res 1994; 54: 4313-20.

[67] Yang P, Ebbert JO, Sun Z, Weinshilboum RM. Role of the glutathione metabolic pathway in lung cancer treatment and prognosis: a review. J Clin Oncol 2006; 24: 1761-9.

[68] Zhang K, Mack P, Wong KP. Glutathione-related mechanisms in cellular resistance to anticancer drugs. Int J Oncol 1998; 12: 87182.

[69] Arner ES, Holmgren A. The thioredoxin system in cancer. Semin Cancer Biol 2006; 16: 420-6.

[70] Nonn L, Berggren M, Powis G. Increased expression of mitochondrial peroxiredoxin-3 (thioredoxin peroxidase-2) protects cancer cells against hypoxia and drug-induced hydrogen peroxidedependent apoptosis. Mol Cancer Res 2003; 1: 682-9.

[71] Powis G, Mustacich D, Coon A. The role of the redox protein thioredoxin in cell growth and cancer. Free Radic Biol Med 2000; 29: 312-22.

[72] Spitz DR, Sim JE, Ridnour LA, Galoforo SS, Lee YJ. Glucose deprivation-induced oxidative stress in human tumor cells. A fundamental defect in metabolism? Ann N Y Acad Sci 2000; 899: 349-62.
[73] Ahmad IM, Aykin-Burns N, Sim JE, et al. Mitochondrial O2*- and $\mathrm{H} 2 \mathrm{O} 2$ mediate glucose deprivation-induced stress in human cancer cells. J Biol Chem 2005; 280: 4254-63.

[74] Jelluma N, Yang X, Stokoe D, Evan GI, Dansen TB, Haas-Kogan DA. Glucose withdrawal induces oxidative stress followed by apoptosis in glioblastoma cells but not in normal human astrocytes. Mol Cancer Res 2006; 4: 319-30.

[75] Nath KA, Ngo EO, Hebbel RP, Croatt AJ, Zhou B, Nutter LM. alpha-Ketoacids scavenge $\mathrm{H} 2 \mathrm{O} 2$ in vitro and in vivo and reduce menadione-induced DNA injury and cytotoxicity. Am J Physiol 1995; 268: C227-C236.

[76] Miwa H, Fujii J, Kanno H, Taniguchi N, Aozasa K. Pyruvate secreted by human lymphoid cell lines protects cells from hydrogen peroxide mediated cell death. Free Radic Res 2000; 33: 45-56.

[77] Ramakrishnan N, Chen R, McClain DE, Bunger R. Pyruvate prevents hydrogen peroxide-induced apoptosis. Free Radic Res 1998; 29: 283-95.

[78] Salahudeen AK, Clark EC, Nath KA. Hydrogen peroxide-induced renal injury. A protective role for pyruvate in vitro and in vivo. $\mathrm{J}$ Clin Invest 1991; 88: 1886-93.

[79] Tuttle SW, Varnes ME, Mitchell JB, Biaglow JE. Sensitivity to chemical oxidants and radiation in $\mathrm{CHO}$ cell lines deficient in oxidative pentose cycle activity. Int J Radiat Oncol Biol Phys 1992; 22: $671-5$.

[80] Averill-Bates DA, Przybytkowski E. The role of glucose in cellular defences against cytotoxicity of hydrogen peroxide in Chinese hamster ovary cells. Arch Biochem Biophys 1994; 312: 52-8.

[81] Shih SF, Wu YH, Hung CH, Yang HY, Lin JY. Abrin triggers cell death by inactivating a thiol-specific antioxidant protein. J Biol Chem 2001; 276: 21870-7.

[82] Bhaskar AS, Deb U, Kumar O, Lakshmana Rao PV. Abrin induced oxidative stress mediated DNA damage in human leukemic cells and its reversal by $\mathrm{N}$-acetylcysteine. Toxicol In vitro 2008; 22: 1902-8.

[83] Dirsch VM, Gerbes AL, Vollmar AM. Ajoene, a compound of garlic, induces apoptosis in human promyeloleukemic cells, accompanied by generation of reactive oxygen species and activation of nuclear factor kappaB. Mol Pharmacol 1998; 53: 402-7.

[84] Li M, Min JM, Cui JR, et al. Z-ajoene induces apoptosis of HL-60 cells: involvement of Bcl-2 cleavage. Nutr Cancer 2002; 42: 241-7.

[85] Jakubikova J, Sedlak J. Garlic-derived organosulfides induce cytotoxicity, apoptosis, cell cycle arrest and oxidative stress in human colon carcinoma cell lines. Neoplasma 2006; 53: 191-9.

[86] Ramoutar RR, Brumaghim JL. Antioxidant and anticancer properties and mechanisms of inorganic selenium, oxo-sulfur, and oxoselenium compounds. Cell Biochem Biophys 2010; 58: 1-23.

[87] Hirsch K, Danilenko M, Giat J, et al. Effect of purified allicin, the major ingredient of freshly crushed garlic, on cancer cell proliferation. Nutr Cancer 2000; 38: 245-54.

[88] Sahu RP, Zhang R, Batra S, Shi Y, Srivastava SK. Benzyl isothiocyanate-mediated generation of reactive oxygen species causes cell cycle arrest and induces apoptosis via activation of MAPK in human pancreatic cancer cells. Carcinogenesis 2009; 30: 1744-53.

[89] Wu CL, Huang AC, Yang JS, et al. Benzyl isothiocyanate (BITC) and phenethyl isothiocyanate (PEITC)-mediated generation of reactive oxygen species causes cell cycle arrest and induces apoptosis via activation of caspase-3, mitochondria dysfunction and nitric oxide (NO) in human osteogenic sarcoma U-2 OS cells. J Orthop Res 2011; 29: 1199-209.

[90] Lin YT, Yang JS, Lin SY, et al. Diallyl disulfide (DADS) induces apoptosis in human cervical cancer Ca Ski cells via reactive oxygen species and $\mathrm{Ca} 2+-$ dependent mitochondria-dependent pathway. Anticancer Res 2008; 28: 2791-9.

[91] Yang JS, Chen GW, Hsia TC, et al. Diallyl disulfide induces apoptosis in human colon cancer cell line (COLO 205) through the induction of reactive oxygen species, endoplasmic reticulum stress, caspases casade and mitochondrial-dependent pathways. Food Chem Toxicol 2009; 47: 171-9.

[92] Zhang G, Wu H, Zhu B, Shimoishi Y, Nakamura Y, Murata Y. Effect of dimethyl sulfides on the induction of apoptosis in human leukemia Jurkat cells and HL-60 cells. Biosci Biotechnol Biochem 2008; 72: 2966-72. 
[93] Davies NJ, Hayden RE, Simpson PJ, et al. AKR1C isoforms represent a novel cellular target for jasmonates alongside their mitochondrial-mediated effects. Cancer Res 2009; 69: 4769-75.

[94] Lu X, Yu H, Ma Q, Shen S, Das UN. Linoleic acid suppresses colorectal cancer cell growth by inducing oxidant stress and mitochondrial dysfunction. Lipids Health Dis 2010; 9: 106.

[95] Cury-Boaventura MF, Curi R. Regulation of reactive oxygen species (ROS) production by $\mathrm{C} 18$ fatty acids in Jurkat and Raji cells. Clin Sci (Lond) 2005; 108: 245-53.

[96] Das UN. Tumoricidal action of cis-unsaturated fatty acids and their relationship to free radicals and lipid peroxidation. Cancer Lett 1991; 56: 235-43.

[97] Vartak S, Robbins ME, Spector AA. The selective cytotoxicity of gamma-linolenic acid (GLA) is associated with increased oxidative stress. Adv Exp Med Biol 1999; 469: 493-8.

[98] Panopoulos A, Harraz M, Engelhardt JF, Zandi E. Iron-mediated $\mathrm{H} 2 \mathrm{O} 2$ production as a mechanism for cell type-specific inhibition of tumor necrosis factor alpha-induced but not interleukin-1betainduced IkappaB kinase complex/nuclear factor-kappaB activation. J Biol Chem 2005; 280: 2912-23.

[99] Hallak M, Vazana L, Shpilberg O, Levy I, Mazar J, Nathan I. A molecular mechanism for mimosine-induced apoptosis involving oxidative stress and mitochondrial activation. Apoptosis 2008; 13: 147-55.

[100] Osseni RA, Rat P, Bogdan A, Warnet JM, Touitou Y. Evidence of prooxidant and antioxidant action of melatonin on human liver cell line HepG2. Life Sci 2000; 68: 387-99.

[101] Bejarano I, Espino J, Barriga C, Reiter RJ, Pariente JA, Rodriguez AB. Pro-oxidant effect of melatonin in tumour leucocytes: relation with its cytotoxic and pro-apoptotic effects. Basic Clin Pharmacol Toxicol 2011; 108: 14-20

[102] Kim JH, Lee SY, Oh SY, et al. Methyl jasmonate induces apoptosis through induction of Bax/Bcl-XS and activation of caspase-3 via ROS production in A549 cells. Oncol Rep 2004; 12: 1233-8.

[103] Rose P, Whiteman M, Huang SH, Halliwell B, Ong CN. betaPhenylethyl isothiocyanate-mediated apoptosis in hepatoma HepG2 cells. Cell Mol Life Sci 2003; 60: 1489-503.

[104] Trachootham D, Zhou Y, Zhang H, et al. Selective killing of oncogenically transformed cells through a ROS-mediated mechanism by beta-phenylethyl isothiocyanate. Cancer Cell 2006; 10: 241-52.

[105] Aquilano K, Filomeni G, Di Renzo L, et al. Reactive oxygen and nitrogen species are involved in sorbitol-induced apoptosis of human erithroleukaemia cells K562. Free Radic Res 2007; 41: 45260.

[106] Singh SV, Srivastava SK, Choi S, et al. Sulforaphane-induced cell death in human prostate cancer cells is initiated by reactive oxygen species. J Biol Chem 2005; 280: 19911-24.

[107] Choi WY, Choi BT, Lee WH, Choi YH. Sulforaphane generates reactive oxygen species leading to mitochondrial perturbation for apoptosis in human leukemia U937 cells. Biomed Pharmacother 2008; 62: 637-44.

[108] Hong SH, Kim J, Kim JM, et al. Apoptosis induction of 2'hydroxycinnamaldehyde as a proteasome inhibitor is associated with ER stress and mitochondrial perturbation in cancer cells. Biochem Pharmacol 2007; 74: 557-65.

[109] Han DC, Lee MY, Shin KD, et al. 2'-benzoyloxycinnamaldehyde induces apoptosis in human carcinoma via reactive oxygen species. J Biol Chem 2004; 279(8): 6911-20.

[110] Innok P, Rukachaisirikul T, Phongpaichit S, Suksamrarn A. Fuscacarpans A-C, new pterocarpans from the stems of Erythrina fusca. Fitoterapia 2010; 81: 518-23.

[111] Lin CN, Chen HL, Yen MH. Flavonoids with DNA strand-scission activity from Rhus javanica var. roxburghiana. Fitoterapia 2008; 79: 32-6.

[112] Banjerdpongchai R, Punyati P, Nakrob A, Pompimon W, Kongtawelert P. 4'-Hydroxycinnamaldehyde from Alpinia galanga (Linn.) Induces Human Leukemic Cell Apoptosis via Mitochondrial and Endoplasmic Reticulum Stress Pathways. Asian Pac J Cancer Prev 2011; 12: 593-8.

[113] Zheng LF, Dai F, Zhou B, Yang L, Liu ZL. Prooxidant activity of hydroxycinnamic acids on DNA damage in the presence of $\mathrm{Cu}(\mathrm{II})$ ions: mechanism and structure-activity relationship. Food Chem Toxicol 2008; 46: 149-56.
[114] Fan GJ, Jin XL, Qian YP, et al. Hydroxycinnamic acids as DNAcleaving agents in the presence of $\mathrm{Cu}(\mathrm{II})$ ions: mechanism, structure-activity relationship, and biological implications. Chemistry 2009; 15: 12889-99.

[115] Hsu YL, Chen CY, Hou MF, et al. 6-Dehydrogingerdione, an active constituent of dietary ginger, induces cell cycle arrest and apoptosis through reactive oxygen species/c-Jun N-terminal kinase pathways in human breast cancer cells. Mol Nutr Food Res 2010; 54: 1307-17.

[116] Chen CY, Tai CJ, Cheng JT, et al. 6-dehydrogingerdione sensitizes human hepatoblastoma Hep G2 cells to TRAIL-induced apoptosis via reactive oxygen species-mediated increase of DR5. J Agric Food Chem 2010; 58: 5604-11.

[117] Wang CC, Chen LG, Lee LT, Yang LL. Effects of 6-gingerol, an antioxidant from ginger, on inducing apoptosis in human leukemic HL-60 cells. In vivo 2003; 17: 641-5.

[118] Nigam N, Bhui K, Prasad S, George J, Shukla Y. [6]-Gingerol induces reactive oxygen species regulated mitochondrial cell death pathway in human epidermoid carcinoma A431 cells. Chem Biol Interact 2009; 181: 77-84.

[119] Pan MH, Hsieh MC, Kuo JM, et al. 6-Shogaol induces apoptosis in human colorectal carcinoma cells via ROS production, caspase activation, and GADD 153 expression. Mol Nutr Food Res 2008; 52: 527-37.

[120] Shieh PC, Chen YO, Kuo DH, et al. Induction of apoptosis by [8]shogaol via reactive oxygen species generation, glutathione depletion, and caspase activation in human leukemia cells. J Agric Food Chem 2010; 58: 3847-54.

[121] Pan MH, Lai CS, Hsu PC, Wang YJ. Acacetin induces apoptosis in human gastric carcinoma cells accompanied by activation of caspase cascades and production of reactive oxygen species. J Agric Food Chem 2005; 53: 620-30.

[122] Shim HY, Park JH, Paik HD, Nah SY, Kim DS, Han YS. Acacetininduced apoptosis of human breast cancer MCF-7 cells involves caspase cascade, mitochondria-mediated death signaling and SAPK/JNK1/2-c-Jun activation. Mol Cells 2007; 24: 95-104.

[123] Yang J, Xiao YL, He XR, Qiu GF, Hu XM. Aesculetin-induced apoptosis through a ROS-mediated mitochondrial dysfunction pathway in human cervical cancer cells. J Asian Nat Prod Res 2010; 12: 185-93.

[124] Lee HZ, Lin CJ, Yang WH, Leung WC, Chang SP. Aloe-emodin induced DNA damage through generation of reactive oxygen species in human lung carcinoma cells. Cancer Lett 2006; 239: 55-63.

[125] Lin ML, Lu YC, Chung JG, et al. Aloe-emodin induces apoptosis of human nasopharyngeal carcinoma cells via caspase-8-mediated activation of the mitochondrial death pathway. Cancer Lett 2010 291: 46-58.

[126] Miyoshi N, Naniwa K, Yamada T, Osawa T, Nakamura Y. Dietary flavonoid apigenin is a potential inducer of intracellular oxidative stress: the role in the interruptive apoptotic signal. Arch Biochem Biophys 2007; 466: 274-82.

[127] Shukla S, Gupta S. Apigenin-induced prostate cancer cell death is initiated by reactive oxygen species and p53 activation. Free Radic Biol Med 2008; 44: 1833-45.

[128] Yoshino M, Haneda M, Naruse M, Murakami K. Prooxidant activity of flavonoids: copper-dependent strand breaks and the formation of 8-hydroxy-2'-deoxyguanosine in DNA. Mol Genet Metab 1999; 68: 468-72.

[129] Taniguchi H, Yoshida T, Horinaka M, et al. Baicalein overcomes tumor necrosis factor-related apoptosis-inducing ligand resistance via two different cell-specific pathways in cancer cells but not in normal cells. Cancer Res 2008; 68: 8918-27.

[130] Ueda S, Nakamura H, Masutani $\mathrm{H}$, et al. Baicalin induces apoptosis via mitochondrial pathway as prooxidant. Mol Immunol 2002; 38 : 781-91.

[131] Lu HF, Hsueh SC, Ho YT, et al. ROS mediates baicalin-induced apoptosis in human promyelocytic leukemia HL-60 cells through the expression of the Gadd 153 and mitochondrial-dependent pathway. Anticancer Res 2007; 27: 117-25.

[132] Mattia CJ, LeBel CP, Bondy SC. Effects of toluene and its metabolites on cerebral reactive oxygen species generation. Biochem Pharmacol 1991; 42: 879-82. 
[133] Bassi AM, Penco S, Canuto RA, Muzio G, Ferro M. Comparative evaluation of cytotoxicity and metabolism of four aldehydes in two hepatoma cell lines. Drug Chem Toxicol 1997; 20: 173-87.

[134] Rubio S, Quintana J, Eiroa JL, Triana J, Estevez F. Betuletol 3methyl ether induces $\mathrm{G}(2)-\mathrm{M}$ phase arrest and activates the sphingomyelin and MAPK pathways in human leukemia cells. Mol Carcinog 2010; 49: 32-43.

[135] Moon DO, Kim MO, Choi YH, Hyun JW, Chang WY, Kim GY. Butein induces $\mathrm{G}(2) / \mathrm{M}$ phase arrest and apoptosis in human hepatoma cancer cells through ROS generation. Cancer Lett 2010; 288: 204-13.

[136] Lee YS. Role of NADPH oxidase-mediated generation of reactive oxygen species in the mechanism of apoptosis induced by phenolic acids in HepG2 human hepatoma cells. Arch Pharm Res 2005; 28: 1183-9.

[137] Hanham AF, Dunn BP, Stich HF. Clastogenic activity of caffeic acid and its relationship to hydrogen peroxide generated during autooxidation. Mutat Res 1983; 116: 333-9.

[138] Luo M, Liu X, Zu Y, et al. Cajanol, a novel anticancer agent from Pigeonpea [Cajanus cajan (L.) Millsp.] roots, induces apoptosis in human breast cancer cells through a ROS-mediated mitochondrial pathway. Chem Biol Interact 2010; 188: 151-60.

[139] Damianaki A, Bakogeorgou E, Kampa M, et al. Potent inhibitory action of red wine polyphenols on human breast cancer cells. J Cell Biochem 2000; 78: 429-41.

[140] Lu N, Chen P, Yang Q, Peng YY. Anti- and pro-oxidant effects of $(+)$-catechin on hemoglobin-induced protein oxidative damage. Toxicol In vitro 2011; 25: 833-8.

[141] Barreto GE, dos Santos GS, Egito ES, El Bacha RS. Catechol inhibits FADH2-linked respiration in rat liver mitochondrial fraction. Acta Cir Bras 2005; 20 (Suppl 1): 72-7.

[142] Barreto G, Madureira D, Capani F, Aon-Bertolino L, Saraceno E, Alvarez-Giraldez LD. The role of catechols and free radicals in benzene toxicity: an oxidative DNA damage pathway. Environ Mol Mutagen 2009; 50: 771-80.

[143] Moran JL, Siegel D, Sun XM, Ross D. Induction of apoptosis by benzene metabolites in HL60 and CD34+ human bone marrow progenitor cells. Mol Pharmacol 1996; 50: 610-5.

[144] Yi ZC, Liu YZ, Li HX, Wang Z. Prooxidant action of chebulinic acid and tellimagrandin I: causing copper-dependent DNA strand breaks. Toxicol In vitro 2009; 23: 425-31.

[145] Saleem A, Husheem M, Harkonen P, Pihlaja K. Inhibition of cancer cell growth by crude extract and the phenolics of Terminalia chebula retz. fruit. J Ethnopharmacol 2002; 81: 327-36.

[146] Rakshit S, Mandal L, Pal BC, et al. Involvement of ROS in chlorogenic acid-induced apoptosis of Bcr-Abl+ CML cells. Biochem Pharmacol 2010; 80: 1662-75.

[147] Yamanaka N, Oda O, Nagao S. Prooxidant activity of caffeic acid, dietary non-flavonoid phenolic acid, on Cu2+-induced low density lipoprotein oxidation. FEBS Lett 1997; 405: 186-90.

[148] Jiang Y, Kusama K, Satoh K, Takayama E, Watanabe S, Sakagami $\mathrm{H}$. Induction of cytotoxicity by chlorogenic acid in human oral tumor cell lines. Phytomedicine 2000; 7: 483-91.

[149] Sugihara N, Arakawa T, Ohnishi M, Furuno K. Anti- and prooxidative effects of flavonoids on metal-induced lipid hydroperoxide-dependent lipid peroxidation in cultured hepatocytes loaded with alpha-linolenic acid. Free Radic Biol Med 1999; 27: 1313-23.

[150] Zhang T, Chen X, Qu L, Wu J, Cui R, Zhao Y. Chrysin and its phosphate ester inhibit cell proliferation and induce apoptosis in Hela cells. Bioorg Med Chem 2004; 12: 6097-105.

[151] Naso L, Ferrer EG, Lezama L, Rojo T, Etcheverry SB, Williams P. Role of oxidative stress in the antitumoral action of a new vanadyl(IV) complex with the flavonoid chrysin in two osteoblast cell lines: relationship with the radical scavenger activity. J Biol Inorg Chem 2010; 15: 889-902.

[152] Kim JA, Lau EK, Pan L, De Blanco EJ. NF-kappaB inhibitors from Brucea javanica exhibiting intracellular effects on reactive oxygen species. Anticancer Res 2010; 30: 3295-300.

[153] Lu CC, Yang JS, Huang AC, et al. Chrysophanol induces necrosis through the production of ROS and alteration of ATP levels in J5 human liver cancer cells. Mol Nutr Food Res 2010; 54: 967-76.

[154] Kuo ML, Huang TS, Lin JK. Curcumin, an antioxidant and antitumor promoter, induces apoptosis in human leukemia cells. Biochim Biophys Acta 1996; 1317: 95-100.
[155] Woo JH, Kim YH, Choi YJ, et al. Molecular mechanisms of curcumin-induced cytotoxicity: induction of apoptosis through generation of reactive oxygen species, down-regulation of Bcl-XL and IAP, the release of cytochrome $\mathrm{c}$ and inhibition of Akt. Carcinogenesis 2003; 24: 1199-208.

[156] Cvorovic J, Tramer F, Granzotto M, Candussio L, Decorti G, Passamonti S. Oxidative stress-based cytotoxicity of delphinidin and cyanidin in colon cancer cells. Arch Biochem Biophys 2010; 501: 151-7.

[157] Fukumoto LR, Mazza G. Assessing antioxidant and prooxidant activities of phenolic compounds. J Agric Food Chem 2000; 48: 3597-604.

[158] Katsuzaki H, Hibasami H, Ohwaki S, et al. Cyanidin 3-O-beta-Dglucoside isolated from skin of black Glycine max and other anthocyanins isolated from skin of red grape induce apoptosis in human lymphoid leukemia Molt 4B cells. Oncol Rep 2003; 10: 297-300.

[159] Feng R, Ni HM, Wang SY, et al. Cyanidin-3-rutinoside, a natural polyphenol antioxidant, selectively kills leukemic cells by induction of oxidative stress. J Biol Chem 2007; 282: 13468-76.

[160] Jin S, Zhang QY, Kang XM, Wang JX, Zhao WH. Daidzein induces MCF-7 breast cancer cell apoptosis via the mitochondrial pathway. Ann Oncol 2010; 21: 263-8.

[161] Lu HF, Wang HL, Chuang YY, et al. Danthron induced apoptosis through mitochondria- and caspase-3-dependent pathways in human brain glioblastoma multiforms GBM 8401 cells. Neurochem Res 2010; 35: 390-8.

[162] Chiang JH, Yang JS, Ma CY, et al. Danthron, an anthraquinone derivative, induces DNA damage and caspase cascades-mediated apoptosis in SNU-1 human gastric cancer cells through mitochondrial permeability transition pores and Bax-triggered pathways. Chem Res Toxicol 2011; 24: 20-9.

[163] Riveiro ME, Moglioni A, Vazquez R, et al. Structural insights into hydroxycoumarin-induced apoptosis in U-937 cells. Bioorg Med Chem 2008; 16: 2665-75.

[164] Hou DX, Ose T, Lin S, et al. Anthocyanidins induce apoptosis in human promyelocytic leukemia cells: structure-activity relationship and mechanisms involved. Int J Oncol 2003; 23: 705-12.

[165] Hou DX, Tong X, Terahara N, Luo D, Fujii M. Delphinidin 3sambubioside, a Hibiscus anthocyanin, induces apoptosis in human leukemia cells through reactive oxygen species-mediated mitochondrial pathway. Arch Biochem Biophys 2005; 440: 101-9.

[166] Hazra B, Das SM, Kumar B, et al. Cytotoxicity of diospyrin and its derivatives in relation to the generation of reactive oxygen species in tumour cells in vitro and in vivo. Chemotherapy 2007; 53: 173-6.

[167] Bhosle SM, Huilgol NG, Mishra KP. Enhancement of radiationinduced oxidative stress and cytotoxicity in tumor cells by ellagic acid. Clin Chim Acta 2005; 359: 89-100.

[168] Lin SY, Lai WW, Ho CC, et al. Emodin induces apoptosis of human tongue squamous cancer SCC-4 cells through reactive oxygen species and mitochondria-dependent pathways. Anticancer Res 2009; 29: 327-35.

[169] Azam S, Hadi N, Khan NU, Hadi SM. Prooxidant property of green tea polyphenols epicatechin and epigallocatechin-3-gallate: implications for anticancer properties. Toxicol In vitro 2004; 18: 555-61.

[170] Chung LY, Cheung TC, Kong SK, et al. Induction of apoptosis by green tea catechins in human prostate cancer DU145 cells. Life Sci 2001; 68: 1207-14

[171] Yang GY, Liao J, Kim K, Yurkow EJ, Yang CS. Inhibition of growth and induction of apoptosis in human cancer cell lines by tea polyphenols. Carcinogenesis 1998; 19: 611-6.

[172] Habtemariam S, Dagne E. Comparative antioxidant, prooxidant and cytotoxic activity of sigmoidin A and eriodictyol. Planta Med 2010; 76: 589-94.

[173] Paya M, Halliwell B, Hoult JR. Interactions of a series of coumarins with reactive oxygen species. Scavenging of superoxide, hypochlorous acid and hydroxyl radicals. Biochem Pharmacol 1992; 44: 205-14.

[174] Yoo CB, Han KT, Cho KS, et al. Eugenol isolated from the essential oil of Eugenia caryophyllata induces a reactive oxygen speciesmediated apoptosis in HL-60 human promyelocytic leukemia cells. Cancer Lett 2005; 225: 41-52. 
[175] Herrerias T, de Oliveira BH, Gomes MA, et al. Eupafolin: Effect on mitochondrial energetic metabolism. Bioorg Med Chem 2008; 16: 854-61.

[176] Chung KS, Choi JH, Back NI, et al. Eupafolin, a flavonoid isolated from Artemisia princeps, induced apoptosis in human cervical adenocarcinoma HeLa cells. Mol Nutr Food Res 2010; 54: 1318-28.

[177] Dabaghi-Barbosa P, Mariante RA, Franco da Cruz LA, et al. Hispidulin: antioxidant properties and effect on mitochondrial energy metabolism. Free Radic Res 2005; 39: 1305-15.

[178] Galati G, Sabzevari O, Wilson JX, O'Brien PJ. Prooxidant activity and cellular effects of the phenoxyl radicals of dietary flavonoids and other polyphenolics. Toxicology 2002; 177: 91-104.

[179] Kim JY, Jeon YK, Jeon W, Nam MJ. Fisetin induces apoptosis in Huh-7 cells via downregulation of BIRC8 and Bcl2L2. Food Chem Toxicol 2010; 48: 2259-64.

[180] Kuo YF, Su YZ, Tseng YH, Wang SY, Wang HM, Chueh PJ. Flavokawain B, a novel chalcone from Alpinia pricei Hayata with potent apoptotic activity: Involvement of ROS and GADD153 upstream of mitochondria-dependent apoptosis in HCT116 cells. Free Radic Biol Med 2010; 49: 214-26.

[181] Paya M, Goodwin PA, De Las HB, Hoult JR. Superoxide scavenging activity in leukocytes and absence of cellular toxicity of a series of coumarins. Biochem Pharmacol 1994; 48: 445-51.

[182] Inoue M, Suzuki R, Koide T, Sakaguchi N, Ogihara Y, Yabu Y. Antioxidant, gallic acid, induces apoptosis in HL-60RG cells. Biochem Biophys Res Commun 1994; 204: 898-904.

[183] Chen HM, Wu YC, Chia YC, et al. Gallic acid, a major component of Toona sinensis leaf extracts, contains a ROS-mediated anticancer activity in human prostate cancer cells. Cancer Lett 2009; 286: 161-71

[184] Ortiz-Sanchez E, Daniels TR, Helguera G, Martinez-Maza O, Bonavida B, Penichet ML. Enhanced cytotoxicity of an antitransferrin receptor IgG3-avidin fusion protein in combination with gambogic acid against human malignant hematopoietic cells: functional relevance of iron, the receptor, and reactive oxygen species. Leukemia 2009; 23: 59-70.

[185] Nie F, Zhang X, Qi Q, et al. Reactive oxygen species accumulation contributes to gambogic acid-induced apoptosis in human hepatoma SMMC-7721 cells. Toxicology 2009; 260: 60-7.

[186] Ullah MF, Ahmad A, Zubair H, et al. Soy isoflavone genistein induces cell death in breast cancer cells through mobilization of endogenous copper ions and generation of reactive oxygen species. Mol Nutr Food Res 2011; 55: 553-9.

[187] Isakovic A, Jankovic T, Harhaji L, et al. Antiglioma action of xanthones from Gentiana kochiana: Mechanistic and structureactivity requirements. Bioorg Med Chem 2008; 16: 5683-94.

[188] Pardo-Andreu GL, Nunez-Figueredo Y, Tudella VG, et al. The anti-cancer agent guttiferone-A permeabilizes mitochondrial membrane: Ensuing energetic and oxidative stress implications. Toxicol Appl Pharmacol 2011; 253: 282-9.

[189] So FV, Guthrie N, Chambers AF, Moussa M, Carroll KK. Inhibition of human breast cancer cell proliferation and delay of mammary tumorigenesis by flavonoids and citrus juices. Nutr Cancer 1996; 26: 167-81.

[190] Choi EJ, Kim GD, Chee KM, Kim GH. Effects of hesperetin on vessel structure formation in mouse embryonic stem (mES) cells. Nutrition 2006; 22: 947-51.

[191] Fabiani R, Fuccelli R, Pieravanti F, De Bartolomeo A, Morozzi G. Production of hydrogen peroxide is responsible for the induction of apoptosis by hydroxytyrosol on HL60 cells. Mol Nutr Food Res 2009; 53: 887-96

[192] Li S, Dong P, Wang J, et al. Icariin, a natural flavonol glycoside, induces apoptosis in human hepatoma SMMC-7721 cells via a ROS/JNK-dependent mitochondrial pathway. Cancer Lett 2010; 298: $222-30$

[193] Atsumi T, Fujisawa S, Tonosaki K. A comparative study of the antioxidant/prooxidant activities of eugenol and isoeugenol with various concentrations and oxidation conditions. Toxicol In vitro 2005; 19: 1025-33.

[194] Fujisawa S, Atsumi T, Ishihara M, Kadoma Y. Cytotoxicity, ROSgeneration activity and radical-scavenging activity of curcumin and related compounds. Anticancer Res 2004; 24: 563-9.
[195] Iwashita K, Kobori M, Yamaki K, Tsushida T. Flavonoids inhibit cell growth and induce apoptosis in B16 melanoma 4A5 cells. Biosci Biotechnol Biochem 2000; 64: 1813-20.

[196] Aithal BK, Kumar MR, Rao BN, Udupa N, Rao BS. Juglone, a naphthoquinone from walnut, exerts cytotoxic and genotoxic effects against cultured melanoma tumor cells. Cell Biol Int 2009; 33: $1039-49$

[197] Ji YB, Qu ZY, Zou X. Juglone-induced apoptosis in human gastric cancer SGC-7901 cells via the mitochondrial pathway. Exp Toxicol Pathol 2011; 63: 69-78.

[198] Sharma V, Joseph C, Ghosh S, Agarwal A, Mishra MK, Sen E Kaempferol induces apoptosis in glioblastoma cells through oxidative stress. Mol Cancer Ther 2007; 6: 2544-53.

[199] Calderon-Montano JM, Burgos-Moron E, Perez-Guerrero C, Lopez-Lazaro M. A review on the dietary flavonoid kaempferol. Mini Rev Med Chem 2011; 11: 298-344.

[200] Zhang SP, Zhou YJ, Liu Y, Cai YQ. Effect of liquiritigenin, a flavanone existed from Radix glycyrrhizae on pro-apoptotic in SMMC-7721 cells. Food Chem Toxicol 2009; 47: 693-701.

[201] Ju W, Wang X, Shi H, Chen W, Belinsky SA, Lin Y. A critical role of luteolin-induced reactive oxygen species in blockage of tumor necrosis factor-activated nuclear factor-kappaB pathway and sensitization of apoptosis in lung cancer cells. Mol Pharmacol 2007; 71: 1381-8.

[202] Lopez-Lazaro M. Distribution and biological activities of the flavonoid luteolin. Mini Rev Med Chem 2009; 9: 31-59.

[203] Katsube N, Iwashita K, Tsushida T, Yamaki K, Kobori M. Induction of apoptosis in cancer cells by Bilberry (Vaccinium myrtillus) and the anthocyanins. J Agric Food Chem 2003; 51: 68-75.

[204] Shih PH, Yeh CT, Yen GC. Effects of anthocyanidin on the inhibition of proliferation and induction of apoptosis in human gastric adenocarcinoma cells. Food Chem Toxicol 2005; 43: 1557-66.

[205] Passi S, Picardo M, Nazzaro-Porro M. Comparative cytotoxicity of phenols in vitro. Biochem J 1987; 245: 537-42.

[206] Kuo HM, Chang LS, Lin YL, et al. Morin inhibits the growth of human leukemia HL-60 cells via cell cycle arrest and induction of apoptosis through mitochondria dependent pathway. Anticancer Res 2007; 27: 395-405.

[207] Wang IK, Lin-Shiau SY, Lin JK. Induction of apoptosis by apigenin and related flavonoids through cytochrome c release and activation of caspase-9 and caspase-3 in leukaemia HL-60 cells. Eur J Cancer 1999; 35: 1517-25.

[208] Sahu SC, Gray GC. Lipid peroxidation and DNA damage induced by morin and naringenin in isolated rat liver nuclei. Food Chem Toxicol 1997; 35: 443-7.

[209] Kanno S, Tomizawa A, Hiura T, et al. Inhibitory effects of naringenin on tumor growth in human cancer cell lines and sarcoma S180-implanted mice. Biol Pharm Bull 2005; 28: 527-30.

[210] Biswal SS, Datta K, Shaw SD, Feng X, Robertson JD, Kehrer JP. Glutathione oxidation and mitochondrial depolarization as mechanisms of nordihydroguaiaretic acid-induced apoptosis in lipoxygenase-deficient FL5.12 cells. Toxicol Sci 2000; 53: 77-83.

[211] Sahu SC, Ruggles DI, O'Donnell MW. Prooxidant activity and toxicity of nordihydroguaiaretic acid in clone-9 rat hepatocyte cultures. Food Chem Toxicol 2006; 44: 1751-7.

[212] Rowe DL, Ozbay T, Bender LM, Nahta R. Nordihydroguaiaretic acid, a cytotoxic insulin-like growth factor-I receptor/HER2 inhibitor in trastuzumab-resistant breast cancer. Mol Cancer Ther 2008; 7: 1900-8.

[213] Chow JM, Huang GC, Shen SC, Wu CY, Lin CW, Chen YC. Differential apoptotic effect of wogonin and nor-wogonin via stimulation of ROS production in human leukemia cells. J Cell Biochem 2008; 103: 1394-404.

[214] Zhang Y, Seeram NP, Lee R, Feng L, Heber D. Isolation and identification of strawberry phenolics with antioxidant and human cancer cell antiproliferative properties. J Agric Food Chem 2008; 56: 670-5.

[215] Hu H, Lee HJ, Jiang C, et al. Penta-1,2,3,4,6-O-galloyl-beta-Dglucose induces p53 and inhibits STAT3 in prostate cancer cells in vitro and suppresses prostate xenograft tumor growth in vivo. Mol Cancer Ther 2008; 7: 2681-91.

[216] Yin S, Dong Y, Li J, Lu J, Hu H. Penta-1,2,3,4,6-O-galloyl-beta-Dglucose induces senescence-like terminal S-phase arrest in human hepatoma and breast cancer cells. Mol Carcinog 2011; 50: 592-600 
[217] Chen PN, Chu SC, Chiou HL, Chiang CL, Yang SF, Hsieh YS. Cyanidin 3-glucoside and peonidin 3-glucoside inhibit tumor cell growth and induce apoptosis in vitro and suppress tumor growth in vivo. Nutr Cancer 2005; 53: 232-43.

[218] Kobori M, Shinmoto H, Tsushida T, Shinohara K. Phloretininduced apoptosis in B16 melanoma 4A5 cells by inhibition of glucose transmembrane transport. Cancer Lett 1997; 119: 207-12.

[219] Srinivas P, Gopinath G, Banerji A, Dinakar A, Srinivas G. Plumbagin induces reactive oxygen species, which mediate apoptosis in human cervical cancer cells. Mol Carcinog 2004; 40: 201-11.

[220] Wang CC, Chiang YM, Sung SC, Hsu YL, Chang JK, Kuo PL. Plumbagin induces cell cycle arrest and apoptosis through reactive oxygen species/c-Jun N-terminal kinase pathways in human melanoma A375.S2 cells. Cancer Lett 2008; 259: 82-98.

[221] Sakano K, Mizutani M, Murata M, Oikawa S, Hiraku Y, Kawanishi S. Procyanidin B2 has anti- and pro-oxidant effects on metalmediated DNA damage. Free Radic Biol Med 2005; 39: 1041-9.

[222] Miura T, Chiba M, Kasai K, et al. Apple procyanidins induce tumor cell apoptosis through mitochondrial pathway activation of caspase-3. Carcinogenesis 2008; 29: 585-93.

[223] Chen WY, Hsieh YA, Tsai CI, et al. Protoapigenone, a natural derivative of apigenin, induces mitogen-activated protein kinasedependent apoptosis in human breast cancer cells associated with induction of oxidative stress and inhibition of glutathione Stransferase pi. Invest New Drugs 2011; 29: 1347-59.

[224] Aboul-Enein HY, Kladna A, Kruk I, Lichszteld K, Michalska T. Effect of psoralens on Fenton-like reaction generating reactive oxygen species. Biopolymers 2003; 72: 59-68.

[225] Wu JZ, Situ ZQ, Wang W, Chen JY, Liu B. Antitumor activity of psoralen on mucoepidermoid carcinoma cell line MEC-1. Chin Med J (Engl) 1992; 105: 913-7.

[226] Chakraborty A, Gupta N, Ghosh K, Roy P. In vitro evaluation of the cytotoxic, anti-proliferative and anti-oxidant properties of pterostilbene isolated from Pterocarpus marsupium. Toxicol In vitro 2010 ; 24 : 1215-28.

[227] Juan ME, Wenzel U, Daniel H, Planas JM. Resveratrol induces apoptosis through ROS-dependent mitochondria pathway in HT-29 human colorectal carcinoma cells. J Agric Food Chem 2008; 56: 4813-8.

[228] Low IC, Chen ZX, Pervaiz S. Bcl-2 modulates resveratrol-induced ROS production by regulating mitochondrial respiration in tumor cells. Antioxid Redox Signal 2010; 13: 807-19.

[229] Lin S, Fujii M, Hou DX. Rhein induces apoptosis in HL-60 cells via reactive oxygen species-independent mitochondrial death pathway. Arch Biochem Biophys 2003; 418: 99-107.

[230] Lin ML, Chen SS, Lu YC, et al. Rhein induces apoptosis through induction of endoplasmic reticulum stress and $\mathrm{Ca}^{2+}$ dependent mitochondrial death pathway in human nasopharyngeal carcinoma cells. Anticancer Res 2007; 27: 3313-22.

[231] Murakami K, Haneda M, Qiao S, Naruse M, Yoshino M. Prooxidant action of rosmarinic acid: transition metal-dependent generation of reactive oxygen species. Toxicol In vitro 2007; 21: 613-7.

[232] Xavier CP, Lima CF, Fernandes-Ferreira M, Pereira-Wilson C. Salvia fruticosa, Salvia officinalis, and rosmarinic acid induce apoptosis and inhibit proliferation of human colorectal cell lines: the role in MAPK/ERK pathway. Nutr Cancer 2009; 61: 564-71.

[233] Park EJ, Lim JH, Nam SI, Park JW, Kwon TK. Rottlerin induces heme oxygenase-1 (HO-1) up-regulation through reactive oxygen species (ROS) dependent and PKC delta-independent pathway in human colon cancer HT29 cells. Biochimie 2010; 92: 110-5.

[234] Ohno I, Eibl G, Odinokova I, et al. Rottlerin stimulates apoptosis in pancreatic cancer cells through interactions with proteins of the Bcl-2 family. Am J Physiol Gastrointest Liver Physiol 2010; 298: G63-G73.

[235] Elema ET, Schripsema J, Malingré TM. Flavones and flavonol glycosides from Eupatorium cannabinum L. Pharm Weekbl Sci 1989; 11(5): 161-4.

[236] Bourogaa E, Bertrand J, Despeaux M, et al. Hammada scoparia flavonoids and rutin kill adherent and chemoresistant leukemic cells. Leuk Res 2011; 35: 1093-101.

[237] Estevez M, Kylli P, Puolanne E, Kivikari R, Heinonen M. Oxidation of skeletal muscle myofibrillar proteins in oil-in-water emulsions: interaction with lipids and effect of selected phenolic compounds. J Agric Food Chem 2008; 56: 10933-40.
[238] Labuda J, Buckova M, Heilerova L, Silhar S, Stepanek I. Evaluation of the redox properties and anti/pro-oxidant effects of selected flavonoids by means of a DNA-based electrochemical biosensor. Anal Bioanal Chem 2003; 376: 168-73.

[239] Chen Z, Silva H, Klessig DF. Active oxygen species in the induction of plant systemic acquired resistance by salicylic acid. Science 1993; 262: 1883-6.

[240] Spitz GA, Furtado CM, Sola-Penna M, Zancan P. Acetylsalicylic acid and salicylic acid decrease tumor cell viability and glucose metabolism modulating 6-phosphofructo-1-kinase structure and activity. Biochem Pharmacol 2009; 77: 46-53.

[241] Simic A, Manojlovic D, Segan D, Todorovic M. Electrochemical behavior and antioxidant and prooxidant activity of natural phenolics. Molecules 2007; 12: 2327-40.

[242] Chen $\mathrm{CH}$, Chern CL, Lin CC, et al. Involvement of reactive oxygen species, but not mitochondrial permeability transition in the apoptotic induction of human SK-Hep-1 hepatoma cells by shikonin. Planta Med 2003; 69: 1119-24.

[243] Hsu PC, Huang YT, Tsai ML, Wang YJ, Lin JK, Pan MH. Induction of apoptosis by shikonin through coordinative modulation of the Bcl-2 family, p27, and p53, release of cytochrome c, and sequential activation of caspases in human colorectal carcinoma cells. J Agric Food Chem 2004; 52: 6330-7.

[244] Kajimoto S, Takanashi N, Kajimoto T, et al. Sophoranone, extracted from a traditional Chinese medicine Shan Dou Gen, induces apoptosis in human leukemia U937 cells via formation of reactive oxygen species and opening of mitochondrial permeability transition pores. Int J Cancer 2002; 99(6): 879-90.

[245] Ramanathan R, Tan CH, Das NP. Cytotoxic effect of plant polyphenols and fat-soluble vitamins on malignant human cultured cells. Cancer Lett 1992; 62: 217-24.

[246] Khan NS, Ahmad A, Hadi SM. Anti-oxidant, pro-oxidant properties of tannic acid and its binding to DNA. Chem Biol Interact 2000; 125: 177-89.

[247] Brusselmans K, Vrolix R, Verhoeven G, Swinnen JV. Induction of cancer cell apoptosis by flavonoids is associated with their ability to inhibit fatty acid synthase activity. J Biol Chem 2005; 280: 5636-45.

[248] Hsu YL, Hou MF, Tsai EM, Kuo PL. Tricetin, a Dietary Flavonoid, Induces Apoptosis through the Reactive Oxygen Species/c-Jun NH(2)-Terminal Kinase Pathway in Human Liver Cancer Cells. J Agric Food Chem 2010; 58: 12547-56.

[249] Han D, Matsumaru K, Rettori D, Kaplowitz N. Usnic acid-induced necrosis of cultured mouse hepatocytes: inhibition of mitochondrial function and oxidative stress. Biochem Pharmacol 2004; 67: 43951 .

[250] Bezivin C, Tomasi S, Rouaud I, Delcros JG, Boustie J. Cytotoxic activity of compounds from the lichen: Cladonia convoluta. Planta Med 2004; 70: 874-7.

[251] Ho K, Yazan LS, Ismail N, Ismail M. Apoptosis and cell cycle arrest of human colorectal cancer cell line HT-29 induced by vanillin. Cancer Epidemiol 2009; 33: 155-60.

[252] Lirdprapamongkol K, Sakurai H, Kawasaki N, et al. Vanillin suppresses in vitro invasion and in vivo metastasis of mouse breast cancer cells. Eur J Pharm Sci 2005; 25: 57-65.

[253] Castor LR, Locatelli KA, Ximenes VF. Pro-oxidant activity of apocynin radical. Free Radic Biol Med 2010; 48: 1636-43.

[254] Wei L, Lu N, Dai Q, et al. Different apoptotic effects of wogonin via induction of $\mathrm{H}(2) \mathrm{O}(2)$ generation and $\mathrm{Ca}(2+)$ overload in malignant hepatoma and normal hepatic cells. J Cell Biochem 2010; 111: $1629-41$.

[255] Yu JQ, Liu HB, Tian DZ, Liu YW, Lei JC, Zou GL. Changes in mitochondrial membrane potential and reactive oxygen species during wogonin-induced cell death in human hepatoma cells. Hepatol Res 2007; 37: 68-76.

[256] Monteghirfo S, Tosetti F, Ambrosini C, et al. Antileukemia effects of xanthohumol in Bcr/Abl-transformed cells involve nuclear factor-kappaB and p53 modulation. Mol Cancer Ther 2008; 7: 2692702 .

[257] Strathmann J, Klimo K, Sauer SW, Okun JG, Prehn JH, Gerhause C. Xanthohumol-induced transient superoxide anion radical formation triggers cancer cells into apoptosis via a mitochondriamediated mechanism. FASEB J 2010; 24: 2938-50. 
[258] Viola G, Fortunato E, Cecconet L, Disaro S, Basso G. Induction of apoptosis in Jurkat cells by photoexcited psoralen derivatives: Implication of mitochondrial dysfunctions and caspases activation. Toxicol In vitro 2007; 21: 211-6.

[259] Joshi PC, Pathak MA. Production of singlet oxygen and superoxide radicals by psoralens and their biological significance. Biochem Biophys Res Commun 1983; 112: 638-46.

[260] Makino T, Tsubouchi R, Murakami K, Haneda M, Yoshino M. Generation of reactive oxygen species and induction of apoptosis of HL60 cells by ingredients of traditional herbal medicine, Shosaiko-to. Basic Clin Pharmacol Toxicol 2006; 98: 401-5.

[261] Lee CS, Kim YJ, Lee MS, Han ES, Lee SJ. 18beta-Glycyrrhetinic acid induces apoptotic cell death in SiHa cells and exhibits a synergistic effect against antibiotic anti-cancer drug toxicity. Life Sci 2008; 83: 481-9.

[262] Yang S, Evens AM, Prachand S, et al. Mitochondrial-mediated apoptosis in lymphoma cells by the diterpenoid lactone andrographolide, the active component of Andrographis paniculata. Clin Cancer Res 2010; 16: 4755-68.

[263] Efferth T, Oesch F. Oxidative stress response of tumor cells: microarray-based comparison between artemisinins and anthracyclines. Biochem Pharmacol 2004; 68: 3-10.

[264] Mercer AE, Copple IM, Maggs JL, O'Neill PM, Park BK. The role of heme and the mitochondrion in the chemical and molecular mechanisms of mammalian cell death induced by the artemisinin antimalarials. J Biol Chem 2011; 286: 987-96.

[265] Singh NP, Lai HC. Artemisinin induces apoptosis in human cancer cells. Anticancer Res 2004; 24: 2277-80.

[266] Park BC, Bosire KO, Lee ES, Lee YS, Kim JA. Asiatic acid induces apoptosis in SK-MEL-2 human melanoma cells. Cancer Lett 2005; 218: 81-90

[267] Zhang YB, Ye YP, Wu XD, Sun HX. Astilbotriterpenic acid induces growth arrest and apoptosis in HeLa cells through mitochondria-related pathways and reactive oxygen species (ROS) production. Chem Biodivers 2009; 6: 218-30.

[268] Liu WK, Ho JC, Cheung FW, Liu BP, Ye WC, Che CT. Apoptotic activity of betulinic acid derivatives on murine melanoma B16 cell line. Eur J Pharmacol 2004; 498: 71-8.

[269] Tibodeau JD, Isham CR, Bible KC. Annatto constituent cis-bixin has selective antimyeloma effects mediated by oxidative stress and associated with inhibition of thioredoxin and thioredoxin reductase. Antioxid Redox Signal 2010; 13: 987-97.

[270] Sun L, Chen T, Wang X, Chen Y, Wei X. Bufalin Induces Reactive Oxygen Species Dependent Bax Translocation and Apoptosis in ASTC-a-1 Cells. Evid Based Complement Alternat Med 2011; 2011: 249090

[271] Ligresti A, Moriello AS, Starowicz K, et al. Antitumor activity of plant cannabinoids with emphasis on the effect of cannabidiol on human breast carcinoma. J Pharmacol Exp Ther 2006; 318: 137587.

[272] McAllister SD, Murase R, Christian RT, et al. Pathways mediating the effects of cannabidiol on the reduction of breast cancer cell proliferation, invasion, and metastasis. Breast Cancer Res Treat 2011; 129: 37-47.

[273] Shrivastava A, Kuzontkoski PM, Groopman JE, Prasad A. Cannabidiol Induces Programmed Cell Death in Breast Cancer Cells by Coordinating the Cross-talk between Apoptosis and Autophagy. Mol Cancer Ther 2011; 10: 1161-72.

[274] Lee MG, Lee KT, Chi SG, Park JH. Costunolide induces apoptosis by ROS-mediated mitochondrial permeability transition and cytochrome C release. Biol Pharm Bull 2001; 24: 303-6.

[275] Park HJ, Kwon SH, Han YN, et al. Apoptosis-Inducing costunolide and a novel acyclic monoterpene from the stem bark of Magnolia sieboldii. Arch Pharm Res 2001; 24: 342-8.

[276] Yasuda S, Yogosawa S, Izutani Y, Nakamura Y, Watanabe H, Sakai T. Cucurbitacin B induces G2 arrest and apoptosis via a reactive oxygen species-dependent mechanism in human colon adenocarcinoma SW480 cells. Mol Nutr Food Res 2010; 54: 559-65.

[277] Wang Y, Che CM, Chiu JF, He QY. Dioscin (saponin)-induced generation of reactive oxygen species through mitochondria dysfunction: a proteomic-based study. J Proteome Res 2007; 6: 470310 .

[278] Liu MJ, Wang Z, Ju Y, Wong RN, Wu QY. Diosgenin induces cell cycle arrest and apoptosis in human leukemia K562 cells with the disruption of $\mathrm{Ca}^{2+}$ homeostasis. Cancer Chemother Pharmacol 2005; 55: 79-90.

[279] Allouche Y, Warleta F, Campos M, et al. Antioxidant, antiproliferative, and pro-apoptotic capacities of pentacyclic triterpenes found in the skin of olives on MCF-7 human breast cancer cells and their effects on DNA damage. J Agric Food Chem 2011; 59: 12130 .

[280] Martin R, Ibeas E, Carvalho-Tavares J, Hernandez M, RuizGutierrez V, Nieto ML. Natural triterpenic diols promote apoptosis in astrocytoma cells through ROS-mediated mitochondrial depolarization and JNK activation. PLoS One 2009; 4: e5975.

[281] Yazlovitskaya EM, Melnykovych G. Selective farnesol toxicity and translocation of protein kinase $\mathrm{C}$ in neoplastic HeLa-S3K and nonneoplastic CF-3 cells. Cancer Lett 1995; 88: 179-83.

[282] Machida K, Tanaka T, Fujita K, Taniguchi M. Farnesol-induced generation of reactive oxygen species via indirect inhibition of the mitochondrial electron transport chain in the yeast Saccharomyces cerevisiae. J Bacteriol 1998; 180: 4460-5.

[283] Joo JH, Jetten AM. Molecular mechanisms involved in farnesolinduced apoptosis. Cancer Lett 2010; 287: 123-35.

[284] Chan WH. Ginkgolide B induces apoptosis and developmental injury in mouse embryonic stem cells and blastocysts. Hum Reprod 2006; 21: 2985-95.

[285] DeFeudis FV, Papadopoulos V, Drieu K. Ginkgo biloba extracts and cancer: a research area in its infancy. Fundam Clin Pharmacol 2003; 17: 405-17.

[286] Kim HE, Oh JH, Lee SK, Oh YJ. Ginsenoside RH-2 induces apoptotic cell death in rat $\mathrm{C} 6$ glioma via a reactive oxygen- and caspasedependent but Bcl-X(L)-independent pathway. Life Sci 1999; 65: L33-L40.

[287] Ham YM, Lim JH, Na HK, et al. Ginsenoside-Rh2-induced mitochondrial depolarization and apoptosis are associated with reactive oxygen species- and Ca2+-mediated c-Jun NH2-terminal kinase 1 activation in HeLa cells. J Pharmacol Exp Ther 2006; 319: 127685.

[288] Gao LW, Zhang J, Yang WH, Wang B, Wang JW. Glaucocalyxin A induces apoptosis in human leukemia HL-60 cells through mitochondria-mediated death pathway. Toxicol In vitro 2011; 25: 5163 .

[289] Singh SV, Choi S, Zeng Y, Hahm ER, Xiao D. Guggulsteroneinduced apoptosis in human prostate cancer cells is caused by reactive oxygen intermediate dependent activation of c-Jun NH2terminal kinase. Cancer Res 2007; 67: 7439-49.

[290] Samudio I, Konopleva M, Safe S, McQueen T, Andreeff M. Guggulsterones induce apoptosis and differentiation in acute myeloid leukemia: identification of isomer-specific antileukemic activities of the pregnadienedione structure. Mol Cancer Ther 2005; 4: 198292.

[291] Chen JC, Lu KW, Lee JH, Yeh CC, Chung JG. Gypenosides induced apoptosis in human colon cancer cells through the mitochondria-dependent pathways and activation of caspase-3. Anticancer Res 2006; 26: 4313-26.

[292] Chen JC, Lu KW, Tsai ML, et al. Gypenosides induced G0/G1 arrest via $\mathrm{CHk} 2$ and apoptosis through endoplasmic reticulum stress and mitochondria-dependent pathways in human tongue cancer SCC-4 cells. Oral Oncol 2009; 45: 273-83.

[293] Hoffmann R, von Schwarzenberg K, Lopez-Anton N, et al. Helenalin bypasses Bcl-2-mediated cell death resistance by inhibiting NFkappaB and promoting reactive oxygen species generation. Biochem Pharmacol 2011; 82: 453-63.

[294] Usta J, Kreydiyyeh S, Knio K, Barnabe P, Bou-Moughlabay Y, Dagher S. Linalool decreases HepG2 viability by inhibiting mitochondrial complexes I and II, increasing reactive oxygen species and decreasing ATP and GSH levels. Chem Biol Interact 2009; 180: $39-46$

[295] Prasad S, Nigam N, Kalra N, Shukla Y. Regulation of signaling pathways involved in lupeol induced inhibition of proliferation and induction of apoptosis in human prostate cancer cells. Mol Carcinog 2008; 47: 916-24.

[296] Yeh S, Hu M. Antioxidant and pro-oxidant effects of lycopene in comparison with beta-carotene on oxidant-induced damage in Hs68 cells. J Nutr Biochem 2000; 11: 548-54 
[297] Yeh SL, Huang CS, Hu ML. Lycopene enhances UVA-induced DNA damage and expression of heme oxygenase-1 in cultured mouse embryo fibroblasts. Eur J Nutr 2005; 44: 365-70.

[298] Muller K, Carpenter KL, Challis IR, Skepper JN, Arends MJ. Carotenoids induce apoptosis in the T-lymphoblast cell line Jurkat E6.1. Free Radic Res 2002; 36: 791-802.

[299] Newman RA, Yang P, Hittelman WN, et al. Oleandrin-mediated oxidative stress in human melanoma cells. J Exp Ther Oncol 2006; 5: 167-81.

[300] Martin R, Carvalho-Tavares J, Ibeas E, Hernandez M, RuizGutierrez V, Nieto ML. Acidic triterpenes compromise growth and survival of astrocytoma cell lines by regulating reactive oxygen species accumulation. Cancer Res 2007; 67: 3741-51.

[301] Fernandes J, Castilho RO, da Costa MR, Wagner-Souza K, Coelho Kaplan MA, Gattass CR. Pentacyclic triterpenes from Chrysobalanaceae species: cytotoxicity on multidrug resistant and sensitive leukemia cell lines. Cancer Lett 2003; 190(2): 165-9.

[302] Babich H, Visioli F. In vitro cytotoxicity to human cells in culture of some phenolics from olive oil. Farmaco 2003; 58: 403-7.

[303] Mazziotti A, Mazzotti F, Pantusa M, Sportelli L, Sindona G. Prooxidant activity of oleuropein determined in vitro by electron spin resonance spin-trapping methodology. J Agric Food Chem 2006; 54: 7444-9.

[304] Han J, Talorete TP, Yamada P, Isoda H. Anti-proliferative and apoptotic effects of oleuropein and hydroxytyrosol on human breast cancer MCF-7 cells. Cytotechnology 2009; 59: 45-53.

[305] Huang J, Wu L, Tashiro S, Onodera S, Ikejima T. Reactive oxygen species mediate oridonin-induced HepG2 apoptosis through p53, MAPK, and mitochondrial signaling pathways. J Pharmacol Sci 2008; 107: 370-9.

[306] Huang YT, Chueh SC, Teng CM, Guh JH. Investigation of ouabain-induced anticancer effect in human androgen-independent prostate cancer PC-3 cells. Biochem Pharmacol 2004; 67: 727-33.

[307] Hou YY, Wu ML, Hwang YC, Chang FR, Wu YC, Wu CC. The natural diterpenoid ovatodiolide induces cell cycle arrest and apoptosis in human oral squamous cell carcinoma Ca9-22 cells. Life Sci 2009; 85: 26-32.

[308] Lin HL, Liu TY, Chau GY, Lui WY, Chi CW. Comparison of 2methoxyestradiol-induced, docetaxel-induced, and paclitaxelinduced apoptosis in hepatoma cells and its correlation with reactive oxygen species. Cancer 2000; 89: 983-94.

[309] Wang YF, Chen CY, Chung SF, Chiou YH, Lo HR. Involvement of oxidative stress and caspase activation in paclitaxel-induced apoptosis of primary effusion lymphoma cells. Cancer Chemother Pharmacol 2004; 54: 322-30.

[310] Wen J, You KR, Lee SY, Song CH, Kim DG. Oxidative stressmediated apoptosis. The anticancer effect of the sesquiterpene lactone parthenolide. J Biol Chem 2002; 277: 38954-64.

[311] Zhang S, Ong CN, Shen HM. Critical roles of intracellular thiols and calcium in parthenolide-induced apoptosis in human colorectal cancer cells. Cancer Lett 2004; 208: 143-53.

[312] Mills JJ, Chari RS, Boyer IJ, Gould MN, Jirtle RL. Induction of apoptosis in liver tumors by the monoterpene perillyl alcohol. Cancer Res 1995; 55: 979-83.

[313] Lebedeva IV, Su ZZ, Vozhilla N, et al. Mechanism of in vitro pancreatic cancer cell growth inhibition by melanoma differentiation-associated gene-7/interleukin-24 and perillyl alcohol. Cancer Res 2008; 68: 7439-47.

[314] Allouche N, Apel C, Martin MT, Dumontet V, Gueritte F, Litaudon M. Cytotoxic sesquiterpenoids from Winteraceae of Caledonian rainforest. Phytochemistry 2009; 70: 546-53.

[315] Machida K, Tanaka T, Taniguchi M. Depletion of glutathione as a cause of the promotive effects of polygodial, a sesquiterpene on the production of reactive oxygen species in Saccharomyces cerevisiae. J Biosci Bioeng 1999; 88: 526-30.

[316] Byun JY, Kim MJ, Eum DY, et al. Reactive oxygen speciesdependent activation of Bax and poly(ADP-ribose) polymerase- 1 is required for mitochondrial cell death induced by triterpenoid pristimerin in human cervical cancer cells. Mol Pharmacol 2009; 76 : 734-44.

[317] Eum DY, Byun JY, Yoon CH, et al. Triterpenoid pristimerin synergizes with taxol to induce cervical cancer cell death through reactive oxygen species-mediated mitochondrial dysfunction. Anticancer Drugs 2011; 22: 763-73.
[318] Wang W, Zhao Y, Rayburn ER, Hill DL, Wang H, Zhang R. In vitro anti-cancer activity and structure-activity relationships of natural products isolated from fruits of Panax ginseng. Cancer Chemother Pharmacol 2007; 59: 589-601.

[319] Liu ZQ, Luo XY, Liu GZ, Chen YP, Wang ZC, Sun YX. In vitro study of the relationship between the structure of ginsenoside and its antioxidative or prooxidative activity in free radical induced hemolysis of human erythrocytes. J Agric Food Chem 2003; 51: 2555-8.

[320] Ni Y, Gong XG, Lu M, Chen HM, Wang Y. Mitochondrial ROS burst as an early sign in sarsasapogenin-induced apoptosis in HepG2 cells. Cell Biol Int 2008; 32: 337-43.

[321] Goncharov I, Weiner L, Vogel Z. Delta9-tetrahydrocannabinol increases $\mathrm{C} 6$ glioma cell death produced by oxidative stress. Neuroscience 2005; 134: 567-74.

[322] Deb DD, Parimala G, Saravana DS, Chakraborty T. Effect of thymol on peripheral blood mononuclear cell PBMC and acute promyelotic cancer cell line HL-60. Chem Biol Interact 2011; 193: 97 106.

[323] Xu B, Guo X, Mathew S, et al. Triptolide simultaneously induces reactive oxygen species, inhibits NF-kappaB activity and sensitizes 5-fluorouracil in colorectal cancer cell lines. Cancer Lett 2010; 291: 200-8

[324] Wu PP, Liu KC, Huang WW, et al. Triptolide induces apoptosis in human adrenal cancer NCI-H295 cells through a mitochondrialdependent pathway. Oncol Rep 2011; 25: 551-7.

[325] Prasad S, Yadav VR, Kannappan R, Aggarwal BB. Ursolic acid, a pentacyclin triterpene, potentiates TRAIL-induced apoptosis through p53-independent up-regulation of death receptors: evidence for the role of reactive oxygen species and JNK. J Biol Chem 2011; 286: 5546-57

[326] Malik F, Kumar A, Bhushan S, et al. Reactive oxygen species generation and mitochondrial dysfunction in the apoptotic cell death of human myeloid leukemia HL-60 cells by a dietary compound withaferin A with concomitant protection by $\mathrm{N}$-acetyl cysteine. Apoptosis 2007; 12: 2115-33.

[327] Mayola E, Gallerne C, Esposti DD, et al. Withaferin A induces apoptosis in human melanoma cells through generation of reactive oxygen species and down-regulation of Bcl-2. Apoptosis 2011; 16: 1014-27.

[328] Swamy SM, Huat BT. Intracellular glutathione depletion and reactive oxygen species generation are important in alpha-hederininduced apoptosis of P388 cells. Mol Cell Biochem 2003; 245 : 127-39.

[329] Legault J, Dahl W, Debiton E, Pichette A, Madelmont JC. Antitumor activity of balsam fir oil: production of reactive oxygen species induced by alpha-humulene as possible mechanism of action. Planta Med 2003; 69: 402-7

[330] Lin KW, Huang AM, Tu HY, et al. Xanthine oxidase inhibitory triterpenoid and phloroglucinol from guttiferaceous plants inhibit growth and induced apoptosis in human NTUB1 cells through a ROS-dependent mechanism. J Agric Food Chem 2011; 59: 407-14.

[331] Kalariya NM, Ramana KV, Srivastava SK, van Kuijk FJ. Carotenoid derived aldehydes-induced oxidative stress causes apoptotic cell death in human retinal pigment epithelial cells. Exp Eye Res 2008; 86: 70-80

[332] Palozza P, Luberto C, Calviello G, Ricci P, Bartoli GM. Antioxidant and prooxidant role of beta-carotene in murine normal and tumor thymocytes: effects of oxygen partial pressure. Free Radic Biol Med 1997; 22: 1065-73.

[333] Schwartz J, Shklar G. The selective cytotoxic effect of carotenoids and alpha-tocopherol on human cancer cell lines in vitro. J Oral Maxillofac Surg 1992; 50: 367-73

[334] Shen DY, Kang JH, Song W, et al. Apoptosis of Human Cholangiocarcinoma Cell Lines induced by beta-Escin through Mitochondrial Caspase-dependent Pathway. Phytother Res 2011; 25: 151926

[335] Zhang Y, Soboloff J, Zhu Z, Berger SA. Inhibition of Ca2+ influx is required for mitochondrial reactive oxygen species-induced endoplasmic reticulum $\mathrm{Ca}^{2+}$ depletion and cell death in leukemia cells. Mol Pharmacol 2006; 70: 1424-34.

[336] Brown J, Higo H, McKalip A, Herman B. Human papillomavirus (HPV) 16 E6 sensitizes cells to atractyloside-induced apoptosis: 
role of p53, ICE-like proteases and the mitochondrial permeability transition. J Cell Biochem 1997; 66: 245-55.

[337] Awad AB, Burr AT, Fink CS. Effect of resveratrol and betasitosterol in combination on reactive oxygen species and prostaglandin release by PC-3 cells. Prostaglandins Leukot Essent Fatty Acids 2005; 72: 219-26.

[338] Arrick BA, Griffo W, Cohn Z, Nathan C. Hydrogen peroxide from cellular metabolism of cystine. A requirement for lysis of murine tumor cells by vernolepin, a glutathione-depleting antineoplastic. J Clin Invest 1985; 76: 567-74.

[339] Lee YJ, Yin HQ, Kim YH, Li GY, Lee BH. Apoptosis inducing effects of 6-methoxydihydrosanguinarine in HT29 colon carcinoma cells. Arch Pharm Res 2004; 27: 1253-7.

[340] Yin HQ, Kim YH, Moon CK, Lee BH. Reactive oxygen speciesmediated induction of apoptosis by a plant alkaloid 6methoxydihydrosanguinarine in HepG2 cells. Biochem Pharmacol 2005; 70: 242-8

[341] Chen TC, Lai KC, Yang JS, et al. Involvement of reactive oxygen species and caspase-dependent pathway in berberine-induced cell cycle arrest and apoptosis in C6 rat glioma cells. Int J Oncol 2009; 34: 1681-90.

[342] Burgeiro A, Gajate C, Dakir eH, Villa-Pulgarin JA, Oliveira PJ, Mollinedo F. Involvement of mitochondrial and B-RAF/ERK signaling pathways in berberine-induced apoptosis in human melanoma cells. Anticancer Drugs 2011; 22(6): 507-18.

[343] Konrath EL, Santin K, Nassif M, Latini A, Henriques A, Salbego C. Antioxidant and pro-oxidant properties of boldine on hippocampal slices exposed to oxygen-glucose deprivation in vitro. Neurotoxicology 2008; 29: 1136-40.

[344] Gerhardt D, Horn AP, Gaelzer MM, et al. Boldine: a potential new antiproliferative drug against glioma cell lines. Invest New Drugs 2009; 27: 517-52

[345] Azam S, Hadi N, Khan NU, Hadi SM. Antioxidant and prooxidant properties of caffeine, theobromine and xanthine. Med Sci Monit 2003; 9: BR325-BR330.

[346] Lu PZ, Lai CY, Chan WH. Caffeine induces cell death via activation of apoptotic signal and inactivation of survival signal in human osteoblasts. Int J Mol Sci 2008; 9: 698-718.

[347] Liu WH, Chang LS. Caffeine induces matrix metalloproteinase-2 (MMP-2) and MMP-9 down-regulation in human leukemia U937 cells via $\mathrm{Ca} 2+/ \mathrm{ROS}$-mediated suppression of $\mathrm{ERK} / \mathrm{c}$-fos pathway and activation of p38 MAPK/c-jun pathway. J Cell Physiol 2010; 224: $775-85$

[348] Li Y, Rory GC, Sang Y, Rosen EM, Laterra J, Xia S. Camptothecin and Fas receptor agonists synergistically induce medulloblastoma cell death: ROS-dependent mechanisms. Anticancer Drugs 2009; 20: 770-8.

[349] Furusawa S, Wu J, Fujimura T, et al. Cepharanthine inhibits proliferation of cancer cells by inducing apoptosis. Methods Find Exp Clin Pharmacol 1998; 20: 87-97.

[350] Biswas KK, Tancharoen S, Sarker KP, Kawahara K, Hashiguchi T, Maruyama I. Cepharanthine triggers apoptosis in a human hepatocellular carcinoma cell line (HuH-7) through the activation of JNK1/2 and the downregulation of Akt. FEBS Lett 2006; 580: 70310.

[351] Yamamoto S, Seta K, Morisco C, Vatner SF, Sadoshima J. Chelerythrine rapidly induces apoptosis through generation of reactive oxygen species in cardiac myocytes. J Mol Cell Cardiol 2001; 33: $1829-48$.

[352] Matkar SS, Wrischnik LA, Hellmann-Blumberg U. Production of hydrogen peroxide and redox cycling can explain how sanguinarine and chelerythrine induce rapid apoptosis. Arch Biochem Biophys 2008; 477: 43-52.

[353] Kaminskyy V, Kulachkovskyy O, Stoika R. A decisive role of mitochondria in defining rate and intensity of apoptosis induction by different alkaloids. Toxicol Lett 2008; 177: 168-81.

[354] DeMarini DM, Lawrence BK. Prophage induction by DNA topoisomerase II poisons and reactive-oxygen species: role of DNA breaks. Mutat Res 1992; 267: 1-17.

[355] Poljakova J, Eckschlager T, Hrabeta J, et al. The mechanism of cytotoxicity and DNA adduct formation by the anticancer drug ellipticine in human neuroblastoma cells. Biochem Pharmacol 2009; 77: $1466-79$
[356] Stiborova M, Rupertova M, Frei E. Cytochrome P450- and peroxidase-mediated oxidation of anticancer alkaloid ellipticine dictates its anti-tumor efficiency. Biochim Biophys Acta 2011; 1814: 17585.

[357] Cai Z, Lin M, Wuchter C, et al. Apoptotic response to homoharringtonine in human wt p53 leukemic cells is independent of reactive oxygen species generation and implicates Bax translocation, mitochondrial cytochrome $\mathrm{c}$ release and caspase activation. Leukemia 2001; 15: 567-74.

[358] Pires dM, Curi TC, Miyasaka CK, Palanch AC, Curi R. Effect of indole acetic acid on oxygen metabolism in cultured rat neutrophil. Gen Pharmacol 1998; 31: 573-8.

[359] Kim DS, Kim SY, Jeong YM, et al. Light-activated indole-3-acetic acid induces apoptosis in g361 human melanoma cells. Biol Pharm Bull 2006; 29: 2404-9.

[360] Shimamoto K, Dewa Y, Ishii Y, et al. Indole-3-carbinol enhances oxidative stress responses resulting in the induction of preneoplastic liver cell lesions in partially hepatectomized rats initiated with diethylnitrosamine. Toxicology 2011; 283: 109-17.

[361] Mandal SK, Biswas R, Bhattacharyya SS, et al. Lycopodine from Lycopodium clavatum extract inhibits proliferation of HeLa cells through induction of apoptosis via caspase-3 activation. Eur J Pharmacol 2010; 626: 115-22.

[362] Singhal PC, Kapasi AA, Reddy K, Franki N, Gibbons N, Ding G. Morphine promotes apoptosis in Jurkat cells. J Leukoc Biol 1999 66: $650-8$.

[363] Lin X, Wang YJ, Li Q, et al. Chronic high-dose morphine treatment promotes SH-SY5Y cell apoptosis via c-Jun N-terminal kinase-mediated activation of mitochondria-dependent pathway. FEBS J 2009; 276: 2022-36.

[364] Zhang Y, Liu H, Jin J, Zhu X, Lu L, Jiang H. The role of endogenous reactive oxygen species in oxymatrine-induced caspase-3dependent apoptosis in human melanoma A375 cells. Anticancer Drugs 2010; 21: 494-501.

[365] Kekre N, Griffin C, McNulty J, Pandey S. Pancratistatin causes early activation of caspase- 3 and the flipping of phosphatidyl serine followed by rapid apoptosis specifically in human lymphoma cells. Cancer Chemother Pharmacol 2005; 56: 29-38.

[366] Siedlakowski P, McLachlan-Burgess A, Griffin C, Tirumalai SS, McNulty J, Pandey S. Synergy of Pancratistatin and Tamoxifen on breast cancer cells in inducing apoptosis by targeting mitochondria. Cancer Biol Ther 2008; 7: 376-84.

[367] Duessel S, Heuertz RM, Ezekiel UR. Growth inhibition of human colon cancer cells by plant compounds. Clin Lab Sci 2008; 21 151-7.

[368] D'Cruz SC, Vaithinathan S, Saradha B, Mathur PP. Piperine activates testicular apoptosis in adult rats. J Biochem Mol Toxicol 2008; 22: 382-8.

[369] Kluza J, Mazinghien R, Degardin K, Lansiaux A, Bailly C. Induction of apoptosis by the plant alkaloid sampangine in human HL-60 leukemia cells is mediated by reactive oxygen species. Eur J Pharmacol 2005; 525: 32-40

[370] Choi WY, Kim GY, Lee WH, Choi YH. Sanguinarine, a benzophenanthridine alkaloid, induces apoptosis in MDA-MB-231 human breast carcinoma cells through a reactive oxygen speciesmediated mitochondrial pathway. Chemotherapy 2008; 54: 279-87.

[371] Jin Q, Kang C, Soh Y, et al. Tetrandrine cytotoxicity and its dual effect on oxidative stress-induced apoptosis through modulating cellular redox states in Neuro 2a mouse neuroblastoma cells. Life Sci 2002; 71: 2053-66

[372] Liu C, Gong K, Mao X, Li W. Tetrandrine induces apoptosis by activating reactive oxygen species and repressing Akt activity in human hepatocellular carcinoma. Int J Cancer 2011; 129: 1519-31.

[373] Ito S, Ihara T, Tamura H, et al. alpha-Tomatine, the major saponin in tomato, induces programmed cell death mediated by reactive oxygen species in the fungal pathogen Fusarium oxysporum. FEBS Lett 2007; 581: 3217-22

[374] Lee ST, Wong PF, Cheah SC, Mustafa MR. Alpha-tomatine induces apoptosis and inhibits nuclear factor-kappa B activation on human prostatic adenocarcinoma PC-3 cells. PLoS One 2011; 6(4) e18915.

[375] Sordet O, Goldman A, Pommier Y. Topoisomerase II and tubulin inhibitors both induce the formation of apoptotic topoisomerase I cleavage complexes. Mol Cancer Ther 2006; 5: 3139-44. 
[376] Benguedouar L, Boussenane HN, Wided K, Alyane M, Rouibah H, Lahouel M. Efficiency of propolis extract against mitochondrial stress induced by antineoplasic agents (doxorubicin and vinblastin) in rats. Indian J Exp Biol 2008; 46: 112-9.

[377] Woiniak A, Drewa G, Wozniak B, et al. The effect of antitumor drugs on oxidative stress in B16 and S91 melanoma cells in vitro. Med Sci Monit 2005; 11: BR22-BR29.

[378] Groninger E, Meeuwsen-De Boer GJ, De Graaf SS, Kamps WA, De Bont ES. Vincristine induced apoptosis in acute lymphoblastic leukaemia cells: a mitochondrial controlled pathway regulated by reactive oxygen species? Int J Oncol 2002; 21: 1339-45.

[379] Pae HO, Oh GS, Choi BM, et al. Induction of apoptosis by 4acetyl-12,13-epoxyl-9-trichothecene-3,15-diol from Isaria japonica Yasuda through intracellular reactive oxygen species formation and caspase-3 activation in human leukemia HL-60 cells. Toxicol In vitro 2003 ; 17: 49-57.

[380] Rogalska A, Koceva-Chyla A, Jozwiak Z. Aclarubicin-induced ROS generation and collapse of mitochondrial membrane potential in human cancer cell lines. Chem Biol Interact 2008; 176: 58-70.

[381] Tsuruga M, Dang Y, Shiono Y, Oka S, Yamazaki Y. Differential effects of vitamin $\mathrm{E}$ and three hydrophilic antioxidants on the actinomycin D-induced and colcemid-accelerated apoptosis in human leukemia CMK-7 cell line. Mol Cell Biochem 2003; 250: 131-

[382] Wang MJ, Liu S, Liu Y, Zheng D. Actinomycin D enhances TRAIL-induced caspase-dependent and -independent apoptosis in SH-SY5Y neuroblastoma cells. Neurosci Res 2007; 59: 40-6.

[383] Garcia-Fernandez LF, Losada A, Alcaide V, et al. Aplidin induces the mitochondrial apoptotic pathway via oxidative stress-mediated JNK and p38 activation and protein kinase $\mathrm{C}$ delta. Oncogene 2002; 21: 7533-44.

[384] Cuadrado A, Garcia-Fernandez LF, Gonzalez L, et al. Aplidin induces apoptosis in human cancer cells via glutathione depletion and sustained activation of the epidermal growth factor receptor, Src, JNK, and p38 MAPK. J Biol Chem 2003; 278: 241-50.

[385] Taddei ML, Chiarugi P, Cuevas C, Ramponi G, Raugei G. Oxidation and inactivation of low molecular weight protein tyrosine phosphatase by the anticancer drug Aplidin. Int J Cancer 2006; 118: 2082-8.

[386] Leaver HA, Williams JR, Smith C, Whittle IR. Intracellular oxidation by human glioma cell populations: effect of arachidonic acid. Prostaglandins Leukot Essent Fatty Acids 2004; 70: 449-53.

[387] Dymkowska D, Wojtczak L. Arachidonic acid-induced apoptosis in rat hepatoma AS-30D cells is mediated by reactive oxygen species. Acta Biochim Pol 2009; 56: 711-5.

[388] Dassonneville L, Wattez N, Baldeyrou B, et al. Inhibition of topoisomerase II by the marine alkaloid ascididemin and induction of apoptosis in leukemia cells. Biochem Pharmacol 2000; 60: 527-37.

[389] Matsumoto SS, Biggs J, Copp BR, Holden JA, Barrows LR. Mechanism of ascididemin-induced cytotoxicity. Chem Res Toxicol 2003; 16: 113-22.

[390] Cunningham ML, Ringrose PS, Lokesh BR. Bleomycin cytotoxicity is prevented by superoxide dismutase in vitro. Cancer Lett 1983; 21: 149-53.

[391] Muller M, Strand S, Hug H, et al. Drug-induced apoptosis in hepatoma cells is mediated by the CD95 (APO-1/Fas) receptor/ligand system and involves activation of wild-type p53. J Clin Invest 1997; 99: 403-13

[392] Gao N, Shang B, Zhang X, et al. Potent antitumor actions of the new antibiotic boningmycin through induction of apoptosis and cellular senescence. Anticancer Drugs 2011; 22: 166-75.

[393] Wang YM, Peng SQ, Zhou Q, et al. Depletion of intracellular glutathione mediates butenolide-induced cytotoxicity in HepG2 cells. Toxicol Lett 2006; 164: 231-8.

[394] Lu HF, Chen YL, Yang JS, et al. Antitumor activity of capsaicin on human colon cancer cells in vitro and colo 205 tumor xenografts in vivo. J Agric Food Chem 2010; 58: 12999-3005.

[395] Yang ZH, Wang XH, Wang HP, Hu LQ, Zheng XM, Li SW. Capsaicin mediates cell death in bladder cancer T24 cells through reactive oxygen species production and mitochondrial depolarization. Urology 2010; 75: 735-41.

[396] Powell AA, LaRue JM, Batta AK, Martinez JD. Bile acid hydrophobicity is correlated with induction of apoptosis and/or growth arrest in HCT116 cells. Biochem J 2001; 356: 481-6.
[397] Qin P, Tang X, Elloso MM, Harnish DC. Bile acids induce adhesion molecule expression in endothelial cells through activation of reactive oxygen species, NF-kappaB, and p38. Am J Physiol Heart Circ Physiol 2006; 291: H741-H747.

[398] Rosignoli P, Fabiani R, De Bartolomeo A, Fuccelli R, Pelli MA, Morozzi G. Genotoxic effect of bile acids on human normal and tumour colon cells and protection by dietary antioxidants and butyrate. Eur J Nutr 2008; 47: 301-9.

[399] Araki Y, Katoh T, Ogawa A, et al. Bile acid modulates transepithelial permeability via the generation of reactive oxygen species in the Caco-2 cell line. Free Radic Biol Med 2005; 39: 769-80.

[400] Zhang R, Gong J, Wang H, Wang L. Bile salts inhibit growth and induce apoptosis of human esophageal cancer cell line. World J Gastroenterol 2005; 11: 5109-16.

[401] Pardhasaradhi BV, Ali AM, Kumari AL, Reddanna P, Khar A. Phycocyanin-mediated apoptosis in AK-5 tumor cells involves down-regulation of Bcl-2 and generation of ROS. Mol Cancer Ther 2003; $2: 1165-70$.

[402] Hoyt MT, Palchaudhuri R, Hergenrother PJ. Cribrostatin 6 induces death in cancer cells through a reactive oxygen species (ROS)mediated mechanism. Invest New Drugs 2011; 29: 562-73.

[403] Ravi D, Muniyappa H, Das KC. Endogenous thioredoxin is required for redox cycling of anthracyclines and p53-dependent apoptosis in cancer cells. J Biol Chem 2005; 280: 40084-96.

[404] Martinez JD, Stratagoules ED, LaRue JM, et al. Different bile acids exhibit distinct biological effects: the tumor promoter deoxycholic acid induces apoptosis and the chemopreventive agent ursodeoxycholic acid inhibits cell proliferation. Nutr Cancer 1998; 31: 111-8.

[405] Zhang X, Jiang L, Geng C, Cao J, Zhong L. The role of oxidative stress in deoxynivalenol-induced DNA damage in HepG2 cells. Toxicon 2009; 54: 513-8.

[406] Krishnaswamy R, Devaraj SN, Padma VV. Lutein protects HT-29 cells against Deoxynivalenol-induced oxidative stress and apoptosis: prevention of NF-kappaB nuclear localization and down regulation of NF-kappaB and Cyclo-Oxygenase-2 expression. Free Radic Biol Med 2010; 49: 50-60.

[407] Kang KS, Wang P, Yamabe N, Fukui M, Jay T, Zhu BT. Docosahexaenoic acid induces apoptosis in MCF-7 cells in vitro and in vivo via reactive oxygen species formation and caspase 8 activation. PLoS One 2010; 5: e10296.

[408] Thayer WS. Adriamycin stimulated superoxide formation in submitochondrial particles. Chem Biol Interact 1977; 19: 265-78.

[409] Kuznetsov AV, Margreiter R, Amberger A, Saks V, Grimm M. Changes in mitochondrial redox state, membrane potential and calcium precede mitochondrial dysfunction in doxorubicin-induced cell death. Biochim Biophys Acta 2011; 1813: 1144-52.

[410] Colquhoun A, Schumacher RI. gamma-Linolenic acid and eicosapentaenoic acid induce modifications in mitochondrial metabolism, reactive oxygen species generation, lipid peroxidation and apoptosis in Walker 256 rat carcinosarcoma cells. Biochim Biophys Acta 2001; 1533: 207-19.

[411] Colquhoun A. Mechanisms of action of eicosapentaenoic acid in bladder cancer cells in vitro: alterations in mitochondrial metabolism, reactive oxygen species generation and apoptosis induction. J Urol 2009; 181: 1885-93.

[412] Zourgui L, Golli EE, Bouaziz C, Bacha H, Hassen W. Cactus (Opuntia ficus-indica) cladodes prevent oxidative damage induced by the mycotoxin zearalenone in Balb/C mice. Food Chem Toxicol 2008; 46: 1817-24.

[413] Banjerdpongchai R, Kongtawelert P, Khantamat O, et al. Mitochondrial and endoplasmic reticulum stress pathways cooperate in zearalenone-induced apoptosis of human leukemic cells. J Hematol Oncol 2010; 3: 50

[414] Kim KN, Heo SJ, Kang SM, Ahn G, Jeon YJ. Fucoxanthin induces apoptosis in human leukemia HL-60 cells through a ROS-mediated Bcl-xL pathway. Toxicol In vitro 2010; 24: 1648-54.

[415] Kuo PL, Chen CY, Hsu YL. Isoobtusilactone A induces cell cycle arrest and apoptosis through reactive oxygen species/apoptosis signal-regulating kinase 1 signaling pathway in human breast cancer cells. Cancer Res 2007; 67: 7406-20.

[416] Chen CY, Liu TZ, Chen CH, et al. Isoobtusilactone A-induced apoptosis in human hepatoma Hep G2 cells is mediated via increased NADPH oxidase-derived reactive oxygen species (ROS) 
production and the mitochondria-associated apoptotic mechanisms. Food Chem Toxicol 2007; 45: 1268-76.

[417] Kuo PL, Chen CY, Tzeng TF, Lin CC, Hsu YL. Involvement of reactive oxygen species/c-Jun $\mathrm{NH}(2)$-terminal kinase pathway in kotomolide A induces apoptosis in human breast cancer cells. Toxicol Appl Pharmacol 2008; 229: 215-26.

[418] Lown JW, Begleiter A, Johnson D, Morgan AR. Studies related to antitumor antibiotics. Part V. Reactions of mitomycin C with DNA examined by ethidium fluorescence assay. Can J Biochem 1976; 54: 110-9.

[419] Wang Y, Gray JP, Mishin V, Heck DE, Laskin DL, Laskin JD. Distinct roles of cytochrome $\mathrm{P} 450$ reductase in mitomycin $\mathrm{C}$ redox cycling and cytotoxicity. Mol Cancer Ther 2010; 9: 1852-63.

[420] Matsunaga T, Tsuji Y, Kaai K, et al. Toxicity against gastric cancer cells by combined treatment with 5-fluorouracil and mitomycin c: implication in oxidative stress. Cancer Chemother Pharmacol 2010; 66: 517-26.

[421] Sato K, Akaike T, Suga M, Ando M, Maeda H. Generation of free radicals from neocarzinostatin mediated by NADPH/cytochrome P450 reductase via activation of enediyne chromophore. Biochem Biophys Res Commun 1994; 205: 1716-23.

[422] Ohnishi S, Murata M, Oikawa S, et al. Oxidative DNA damage by an N-hydroxy metabolite of the mutagenic compound formed from norharman and aniline. Mutat Res 2001; 494: 63-72.

[423] Zheng L, Yan X, Han X, et al. Identification of norharman as the cytotoxic compound produced by the sponge (Hymeniacidon perleve)-associated marine bacterium Pseudoalteromonas piscicida and its apoptotic effect on cancer cells. Biotechnol Appl Biochem 2006; 44: 135-42.

[424] Baudrimont I, Betbeder AM, Gharbi A, Pfohl-Leszkowicz A, Dirheimer G, Creppy EE. Effect of superoxide dismutase and catalase on the nephrotoxicity induced by subchronical administration of ochratoxin A in rats. Toxicology 1994; 89: 101-11.

[425] Arbillaga L, Azqueta A, Ezpeleta O, Lopez dC. Oxidative DNA damage induced by Ochratoxin A in the HK-2 human kidney cell line: evidence of the relationship with cytotoxicity. Mutagenesis 2007; $22: 35-42$

[426] El Golli BE, Rodriguez-Enfedaque A, Bouaziz C, Ladjimi M, Renaud F, Bacha H. Toxicities induced in cultured human hepatocarcinoma cells exposed to ochratoxin A: oxidative stress and apoptosis status. J Biochem Mol Toxicol 2009; 23: 87-96.

[427] Wu TS, Liao YC, Yu FY, Chang CH, Liu BH. Mechanism of patulin-induced apoptosis in human leukemia cells (HL-60). Toxicol Lett 2008; 183: 105-11.

[428] Ferrer E, Juan-Garcia A, Font G, Ruiz MJ. Reactive oxygen species induced by beauvericin, patulin and zearalenone in CHO-K1 cells. Toxicol In vitro 2009; 23: 1504-9.

[429] Zhou SM, Jiang LP, Geng CY, Cao J, Zhong LF. Patulin-induced oxidative DNA damage and p53 modulation in HepG2 cells. Toxicon 2010; 55: 390-5.

[430] Russo A, Piovano M, Clericuzio M, et al. Putrescine-1,4dicinnamide from Pholiota spumosa (Basidiomycetes) inhibits cell growth of human prostate cancer cells. Phytomedicine 2007; 14: 185-91.

[431] Lin RJ, Cheng MJ, Huang JC, et al. Cytotoxic compounds from the stems of Cinnamomum tenuifolium. J Nat Prod 2009; 72: 1816-24.
[432] Chaudhari M, Jayaraj R, Bhaskar AS, Lakshmana Rao PV. Oxidative stress induction by T-2 toxin causes DNA damage and triggers apoptosis via caspase pathway in human cervical cancer cells. Toxicology 2009; 262: 153-61.

[433] Wu J, Jing L, Yuan H, Peng SQ. T-2 toxin induces apoptosis in ovarian granulosa cells of rats through reactive oxygen speciesmediated mitochondrial pathway. Toxicol Lett 2011; 202: 168-77.

[434] Lim SC, Duong HQ, Choi JE, et al. Lipid raft-dependent death receptor 5 (DR5) expression and activation are critical for ursodeoxycholic acid-induced apoptosis in gastric cancer cells. Carcinogenesis 2011; 32: 723-31.

[435] Murata M, Kawanishi S. Oxidative DNA damage by vitamin A and its derivative via superoxide generation. J Biol Chem 2000; 275: 2003-8.

[436] Klamt F, Dal Pizzol F, Gelain DP, et al. Vitamin A treatment induces apoptosis through an oxidant-dependent activation of the mitochondrial pathway. Cell Biol Int 2008; 32: 100-6.

[437] Gasowska-Giszczak U, Darmochwal-Kolarz D, Kwasniewska A, Dziubinska-Parol I, Rolinski J, Oleszczuk J. Apoptosis of HeLa cell lines incubated with retinol. Eur J Obstet Gynecol Reprod Biol 2005; 119: 119-22.

[438] Chen Q, Espey MG, Sun AY, et al. Pharmacologic doses of ascorbate act as a prooxidant and decrease growth of aggressive tumo xenografts in mice. Proc Natl Acad Sci U S A 2008; 105: 11105-9.

[439] Du J, Martin SM, Levine M, et al. Mechanisms of ascorbateinduced cytotoxicity in pancreatic cancer. Clin Cancer Res 2010; 16: $509-20$.

[440] Chen WJ, Huang YT, Wu ML, Huang TC, Ho CT, Pan MH. Induction of apoptosis by vitamin D2, ergocalciferol, via reactive oxygen species generation, glutathione depletion, and caspase activation in human leukemia Cells. J Agric Food Chem 2008; 56: 2996-3005.

[441] Koren R, Hadari-Naor I, Zuck E, Rotem C, Liberman UA, Ravid A. Vitamin D is a prooxidant in breast cancer cells. Cancer Res 2001; 61: 1439-44.

[442] Narvaez CJ, Welsh J. Role of mitochondria and caspases in vitamin D-mediated apoptosis of MCF-7 breast cancer cells. J Biol Chem 2001; 276: 9101-7.

[443] Shibayama-Imazu T, Sonoda I, Sakairi S, et al. Production of superoxide and dissipation of mitochondrial transmembrane potential by vitamin $\mathrm{K} 2$ trigger apoptosis in human ovarian cancer TYK-nu cells. Apoptosis 2006; 11: 1535-43.

[444] Shibayama-Imazu T, Aiuchi T, Nakaya K. Vitamin K2-mediated apoptosis in cancer cells: role of mitochondrial transmembrane potential. Vitam Horm 2008; 78: 211-26.

[445] Jamison JM, Gilloteaux J, Nassiri MR, Venugopal M, Neal DR, Summers JL. Cell cycle arrest and autoschizis in a human bladder carcinoma cell line following Vitamin C and Vitamin K3 treatment. Biochem Pharmacol 2004; 67: 337-51.

[446] Akiyoshi T, Matzno S, Sakai M, Okamura N, Matsuyama K. The potential of vitamin $\mathrm{K} 3$ as an anticancer agent against breast cancer that acts via the mitochondria-related apoptotic pathway. Cancer Chemother Pharmacol 2009; 65: 143-50. 